\title{
Article \\ Behind Brain Metastases Formation: Cellular and Molecular Alterations and Blood-Brain Barrier Disruption
}

\author{
Joana Godinho-Pereira ${ }^{1,2}{ }^{(0)}$, Ana Rita Garcia ${ }^{1,2}$, Inês Figueira ${ }^{1,3(\mathbb{C}}$, Rui Malhó ${ }^{4}$ and Maria Alexandra Brito ${ }^{1,2, *(\mathbb{C})}$ \\ 1 iMed.ULisboa-Research Institute for Medicines, Faculty of Pharmacy, Universidade de Lisboa, \\ Av. Prof. Gama Pinto, 1649-003 Lisbon, Portugal; joanagpereira@ff.ulisboa.pt (J.G.-P.); \\ arcgarcia@campus.ul.pt (A.R.G.); ifigueira@farm-id.pt (I.F.) \\ 2 Department of Pharmaceutical Sciences and Medicines, Faculty of Pharmacy, Universidade de Lisboa, \\ Av. Prof. Gama Pinto, 1649-003 Lisbon, Portugal \\ 3 Farm-ID—Faculty of Pharmacy Association for Research and Development, Av. Prof. Gama Pinto, \\ 1649-003 Lisbon, Portugal \\ 4 BioISI-Biosystems and Integrative Sciences Institute, Faculty of Sciences, Universidade de Lisboa, \\ Campo Grande 016, 1749-016 Lisbon, Portugal; rmmalho@fc.ul.pt \\ * Correspondence: mariabrito@campus.ul.pt; Tel.: +351-217946449
}

Citation: Godinho-Pereira, J.; Garcia, A.R.; Figueira, I.; Malhó, R.; Brito, M.A. Behind Brain Metastases Formation: Cellular and Molecular Alterations and Blood-Brain Barrier Disruption. Int. J. Mol. Sci. 2021, 22, 7057. https://doi.org/10.3390/ ijms 22137057

Academic Editor: Ryszard Pluta

Received: 23 May 2021

Accepted: 26 June 2021

Published: 30 June 2021

Publisher's Note: MDPI stays neutral with regard to jurisdictional claims in published maps and institutional affiliations.

Copyright: (c) 2021 by the authors. Licensee MDPI, Basel, Switzerland. This article is an open access article distributed under the terms and conditions of the Creative Commons Attribution (CC BY) license (https:/ / creativecommons.org/licenses/by/ $4.0 /)$.

\begin{abstract}
Breast cancer (BC) brain metastases is a life-threatening condition to which accounts the poor understanding of BC cells' (BCCs) extravasation into the brain, precluding the development of preventive strategies. Thus, we aimed to unravel the players involved in the interaction between BCCs and blood-brain barrier (BBB) endothelial cells underlying BBB alterations and the transendothelial migration of malignant cells. We used brain microvascular endothelial cells (BMECs) as a BBB in vitro model, under conditions mimicking shear stress to improve in vivo-like BBB features. Mixed cultures were performed by the addition of fluorescently labelled BCCs to distinguish individual cell populations. BCC-BMEC interaction compromised BBB integrity, as revealed by junctional proteins ( $\beta$-catenin and zonula occludens- 1 ) disruption and caveolae (caveolin-1) increase, reflecting paracellular and transcellular hyperpermeability, respectively. Both BMECs and BCCs presented alterations in the expression pattern of connexin 43, suggesting the involvement of the gap junction protein. Myosin light chain kinase and phosphorylated myosin light chain were upregulated, revealing the involvement of the endothelial cytoskeleton in the extravasation process. $\beta 4$-Integrin and focal adhesion kinase were colocalised in malignant cells, reflecting molecular interaction. Moreover, BCCs exhibited invadopodia, attesting migratory properties. Collectively, hub players involved in BC brain metastases formation were unveiled, disclosing possible therapeutic targets for metastases prevention.
\end{abstract}

Keywords: blood-brain barrier; breast cancer brain metastases; extravasation; paracellular and transcellular migration; adhesion; cellular communication

\section{Introduction}

Breast cancer $(\mathrm{BC})$ represents the most commonly diagnosed and leading cause of neoplastic disease in woman, with more than 2.2 million new cases and 684,996 deaths in 2020 [1]. Advances in the early detection and treatment of the primary tumour have led to an increase in cancer survivors [2], rendering the largely incurable metastatic recurrence the foremost concern for cancer patients [3]. Indeed, circa 15\% of BC patients present brain metastases [4]. BC brain metastases particularly occur in triple negative BC, and represent a poor prognosis condition, with a low rate of patient survival $[5,6]$.

It is known that BC brain metastases formation occurs through a process named the metastatic cascade [7] that involves the exit of BC cells (BCCs) from the mammary ducts (invasion), the entrance of malignant cells in circulation (intravasation), their survival in the bloodstream and their arrival to the target organ, where they can transmigrate 
(extravasation) through the blood-brain barrier (BBB) and finally colonise the brain [7]. The extravasation process comprises three major sequential steps, rolling, adhesion and transendothelial migration (TEM) [8], involving several receptors and ligands such as selectins, integrins and members of the immunoglobulin superfamily of cell adhesion molecules $[9,10]$.

Adhesion molecules and signalling proteins, such as focal adhesion kinase (FAK), can have a determinant role in the adhesion process of both endothelial and BCCs [11,12]. FAK's importance towards BCC migration and invasion mechanisms [13], as well as in endothelial cells' (ECs) permeability upon contact with BCCs $[14,15]$ have been demonstrated. However, FAK's function in brain microvascular EC (BMEC)-BCC interaction during extravasation remains under-investigated.

In order to extravasate into the brain parenchyma, BCCs must surpass the BBB [16]. The anatomical basis of the BBB is formed by BMECs, which are characterised by the presence of strong junctional complexes, mostly formed by tight and adherens junctions (TJs and AJs, respectively), which account for the restricted BBB permeability [16]. The mechanical forces promoted by the blood flow to which BMECs are subjected, known as the fluidic shear stress (SS), lead to cytoskeleton rearrangements (i.e., cell elongation and alignment), barrier tightness and restricted permeability as a consequence of TJs' and $\mathrm{AJs} \mathrm{s}^{\prime}$ increased expression $[17,18]$. Despite the obstacle posed by the BBB, BCCs are able to cross it, as revealed by the establishment of brain metastases [19].

Although the paracellular route seems to be the most commonly used by tumour cells [20-22], the transcellular one has also been reported as a possible way of BCCs to transpose the BBB $[23,24]$, with a better understanding of the pathway used by the BCCs during TEM being imperative. In fact, the activation of endothelial protein kinases such as myosin light chain kinase (MLCK), which controls myosin light chain (MLC) phosphorylation, prompting stress fibre formation [25] and cytoskeleton contractility [26], is thought to play a key role in tumour cell migration [27]. Moreover, endothelial MLCK was already identified as a player in transcellular BCC intravasation [28]; however, its role in extravasation has been underexplored.

Vesicular transcytosis is intimately associated with transcellular transmigration, where caveolin-1 (cav-1) is described to play a role, particularly in BMECs, regulating BBB permeability [29]. Interestingly, cav-1 increased expression in the microvasculature along in vivo BC brain metastasis formation has recently been reported by our team [19], suggesting an increase in transcellular permeability. As far as cancer is concerned, cav- 1 has been described to bear a role in BCC metastatic mechanisms, though conflicting information has been provided, with reports that its overexpression has either pro- or anti-metastatic properties [30,31]. In fact, cav-1 upregulation was associated with resistance to anoikis, a programmed type of apoptosis resulting from the loss of cell-matrix adhesion [32], in line with its pro-metastatic activity, while decreasing the proliferation and migration of the BCCs with brain tropism, 231-BR [33], consistent with cav-1's anti-metastatic role.

Cell communication is paramount to extravasation and tumour formation. Gap junction proteins, such as connexin 43 (Cx43), allow cellular communication by the formation of intercellular channels among adjacent cells, impacting cell-cell adhesion, migration, proliferation, and permeability [34-36]. Endothelial Cx43, in particular, was described to have a role in cell communication and BBB function [35]. However, authors are not in agreement on Cx43's role in metastases development, with some describing it as a tumour suppressor and others as a key molecule involved in tumourigenesis [34,37]. Nevertheless, Cx43 appears to play a role in cancer cell transmigration as it localises in the interface between endothelial and BCCs during this process, being involved in BCC migration induction [38]. Accordingly, along in vivo $\mathrm{BC}$ brain metastasis formation, intercellular communication via $\mathrm{C} \times 43$ was indicated by the protein expression among $\mathrm{BCCs}$, and between $\mathrm{BCC}$ and BMECs [19].

In this work, we aimed to unravel key players involved along the interaction between triple negative BCCs and BMECs, which underlay BBB alterations and transendothelial 
migration mechanisms of malignant cells towards the brain. We took advantage of an in-house improved BBB in vitro model, which better mimics the in vivo features by encompassing the effect of SS [17], where fluorescently labelled triple negative BCCs were added. Using this cell model of $\mathrm{BC}$ brain metastasis formation, we provide evidence regarding signalling molecules involved in BCCs' migratory phenotype, as well as in their adhesion and TEM across the BBB endothelium, essential for BCC extravasation and BC brain metastasis formation. Along BCC-BMEC interaction, $\mathrm{Cx} 43$ delocalisation was observed, pointing to a role of the gap junction protein. Endothelial vesicular transcytosis activation via cav-1, cytoskeleton-associated kinase expression with concomitant cytoskeleton contractility and rearrangements, and junctional complex disturbances associated with endothelial monolayer impairment were observed, indicating both paracellular and transcellular alterations during TEM, as well as BBB disruption. Collectively, with this work, we disclosed the molecular players and mechanisms involved in BCC-BMEC interaction, possible targets for modulation to prevent the BCCs' extravasation and BC brain metastases development, either by BBB properties' improvement or towards the decrease in BCCs' adhesion and migratory properties.

\section{Results}

\subsection{SS Promotes In Vivo-Like BBB Properties}

Our previous study demonstrated that monolayers of the brain endothelioma cell line b.End5 exposed to orbital rotation to mimic physiological values of SS $\left(1.5 \mathrm{dyn} / \mathrm{cm}^{2}\right)$ present an increased expression of junctional complexes and an elongated and aligned morphology, in line with the in vivo properties of BMECs [17]. To characterise the behaviour of the BBB endothelium under conditions mimicking physiological SS during the timeframe of subsequent experiments, in which mixed cultures are initiated $24 \mathrm{~h}$ after the induction of SS and analyses are performed thereafter starting at $1 \mathrm{~h}$ and running until $24 \mathrm{~h}$ ( 25 and $48 \mathrm{~h}$ of total time, respectively), immunofluorescence analysis of the TJ and AJ proteins, zonula occludens (ZO)-1 and $\beta$-catenin, respectively, was performed (Figure 1).

We observed that both junctional proteins are expressed by b.End5 cells, and that they are increasingly expressed at the membrane level along time (Figure 1A,B). Moreover, an increasing exposure to orbital rotation promoted a change in cell morphology, from rounded to elongated, with a progressive alignment of the cells. Semi-quantitative analysis revealed an increase in ZO-1 fluorescence intensity $(p<0.05$, Figure 1C) and a reduction in the number of membrane gaps ( $p<0.001$, Figure 1D) at $48 \mathrm{~h}$ as compared with $25 \mathrm{~h}$. An increase in $\beta$-catenin fluorescence intensity $(p<0.001$, Figure 1E), together with an increase in cell elongation $(p<0.001$; Figure $1 \mathrm{~F})$, was also noticeable after $48 \mathrm{~h}$ of orbital rotation in comparison with the $25 \mathrm{~h}$ patterns.

Altogether, these findings corroborate our previous results that orbital rotation is a mechanical stimulus that promotes the expression of junctional proteins, as well as their localisation at the plasma membrane, and improves BBB morphological features, in line with the SS effects in vivo. 


\section{A}
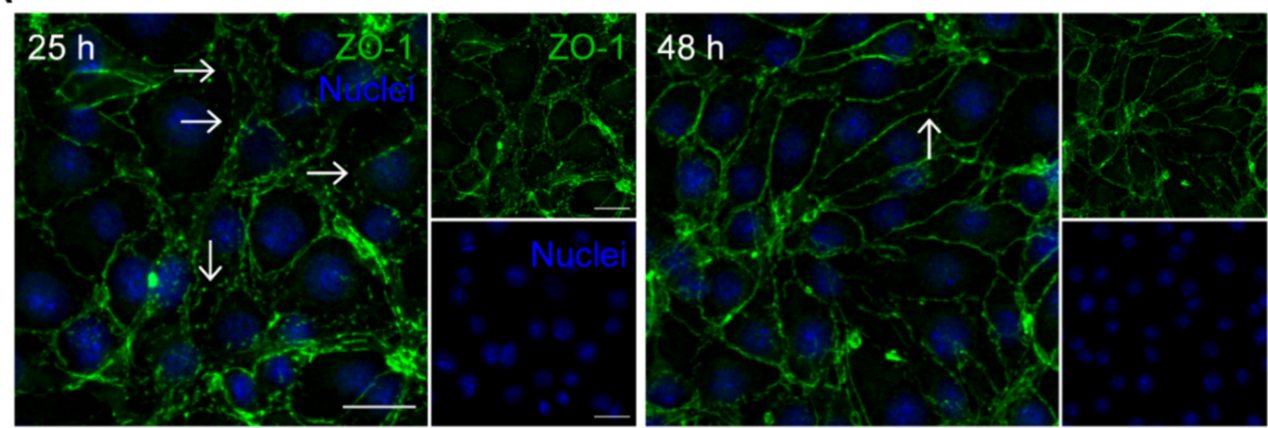

B
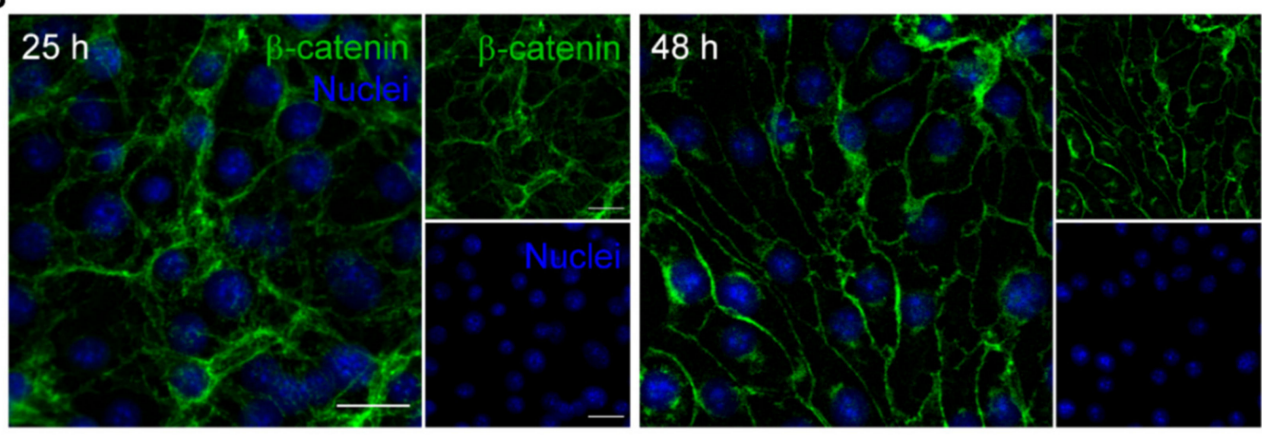

C

D

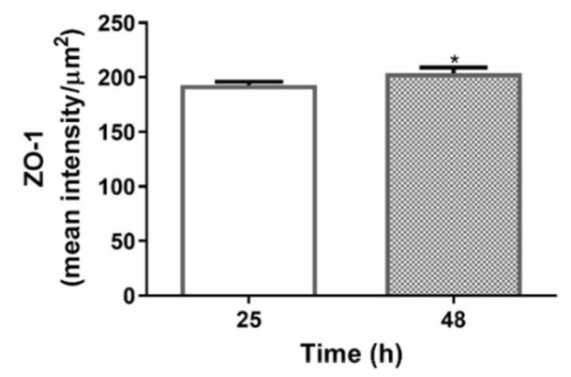

E

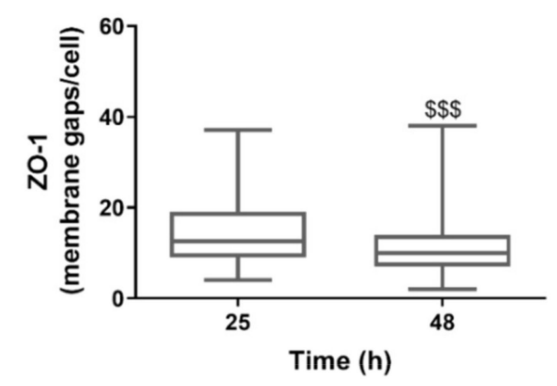

$\mathbf{F}$
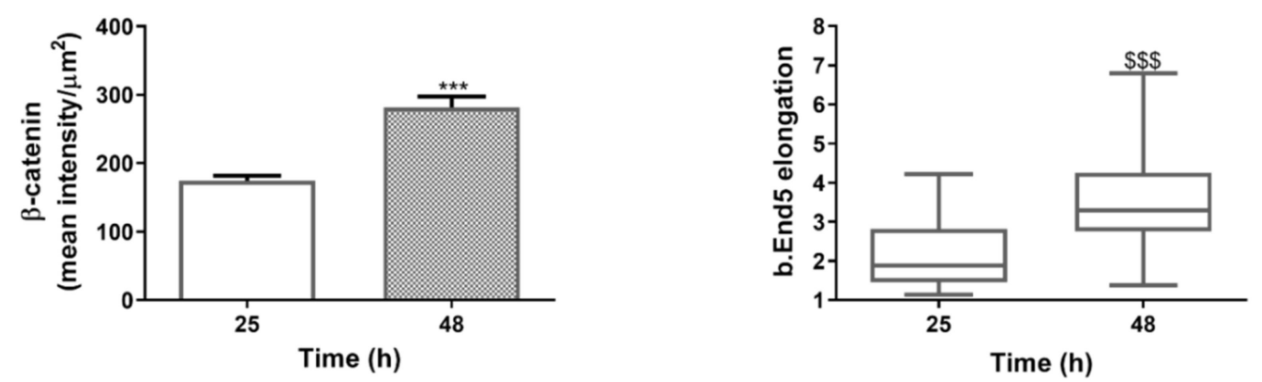

Figure 1. Shear stress (SS) promotes brain microvascular endothelial properties. Confluent monolayers of the brain endothelioma cell line b.End5 were exposed to physiological laminar non-pulsatile SS for 25 and $48 \mathrm{~h}$. SS effects were evaluated by immunofluorescence analysis of the tight and adherens junction proteins (A) zonula occludens (ZO)- 1 and (B) $\beta$-catenin, respectively, which showed a delocalisation of the proteins towards the cell membrane and a decrease in membrane gaps (white arrows). Hoechst 33342 was used as counterstaining for nuclei (blue). Scale bar: $20 \mu \mathrm{m}$. Semiquantitative analysis of ZO-1 expression showed (C) a slight increase in staining intensity, from 25 to $48 \mathrm{~h}$, and a (D) marked decrease in cell membrane gaps, while $\beta$-catenin presented (E) a notorious increase in fluorescence intensity, and (F) a clear cellular elongation. Data are given as means $\pm \operatorname{SEM}(n=3,10$ fields/condition). A Student's $t$-test for mean intensity and a Mann-Whitney test for membrane gaps and cell elongation were used to evaluate the significant differences, where ${ }^{*} p<0.05$ and ${ }^{* * *} p<0.001$ or ${ }^{\$ \$} p<0.001$ denote differences between the indicated timepoints. 


\subsection{Adherens and Tight Junctional Complexes Are Compromised during BMEC-BCC Interaction}

To establish the consequences of endothelial-malignant cells interaction on barrier integrity, we analysed the expression of $\beta$-catenin (Figure 2), an AJ protein fundamental to intercellular adhesion and barrier restricted permeability [16], as well as of ZO-1 (Figure 3), a TJ accessory protein essential to barrier properties' maintenance [16,39].

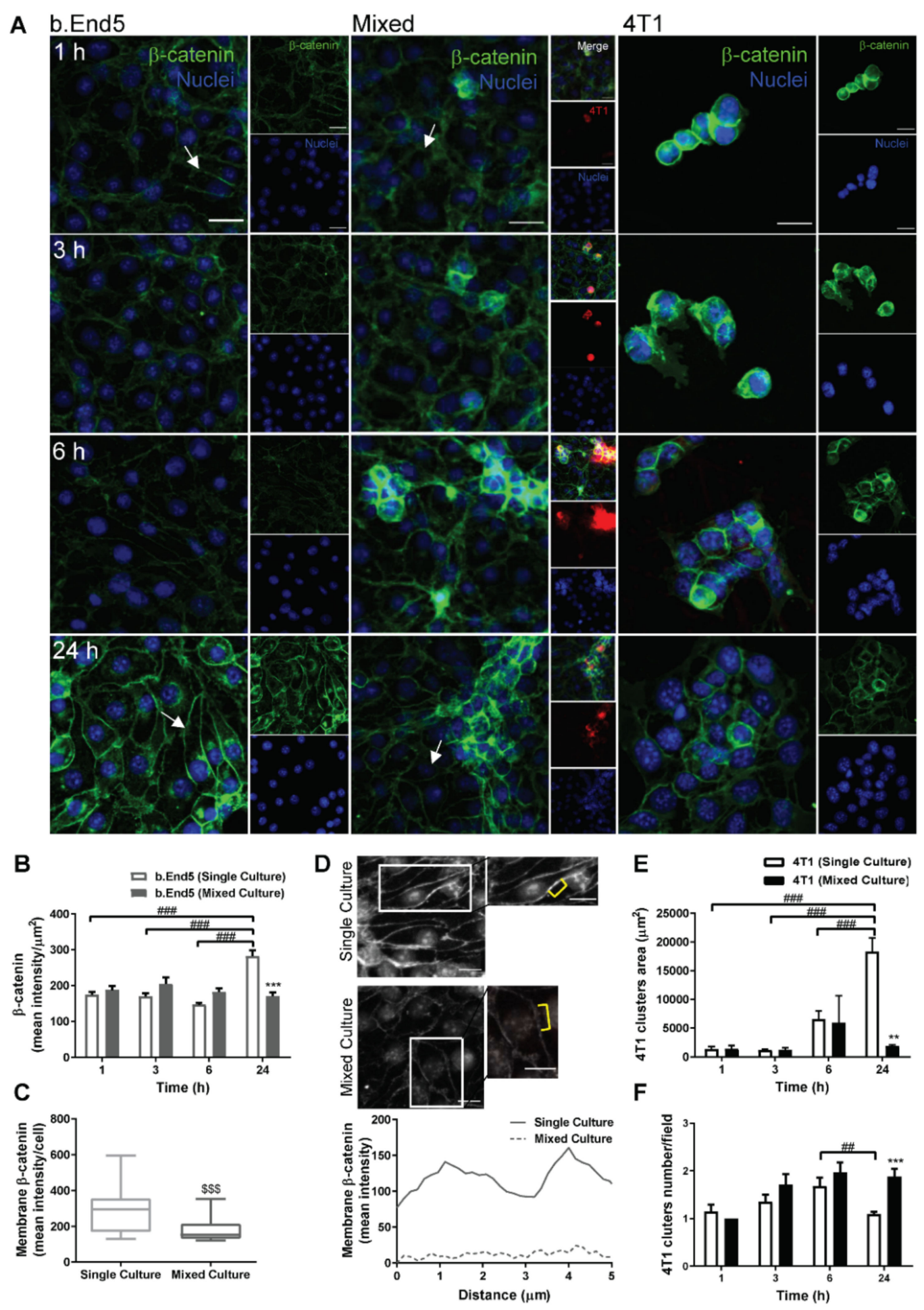

Figure 2. Adherens junctions are compromised during interaction between breast cancer cells and brain microvascular endothelial cells. Confluent monolayers of the brain endothelioma cell line b.End5 under physiological laminar non-pulsatile shear stress were exposed to 4T1 breast cancer cells (previously labelled with CellTracker ${ }^{\text {TM }}$ DMTPX Red Dye) for 1, 3, 6 and $24 \mathrm{~h}$ and the expression of the adherens junction protein, $\beta$-catenin, in single and mixed cultures was evaluated by immuno- 
fluorescence analysis. (A) Analysis of the expression of $\beta$-catenin (green) revealed that the protein is present in both cell types, with a different cellular distribution in mixed cultures as compared with single ones, and further revealed a loss of elongation in b.End5 cells exposed to $4 \mathrm{~T} 1$ cells (white arrows). Hoechst 33342 was used as counterstaining for nuclei (blue). Scale bar: $20 \mu \mathrm{m}$. Semi-quantitative analysis revealed (B) a decrease in endothelial $\beta$-catenin intensity in mixed culture at $24 \mathrm{~h},(\mathbf{C})$ particularly notorious at the cell membrane, which was validated by the (D) plot profile analysis of the membrane region pointed out with the yellow brackets. Scale bar: $20 \mu \mathrm{m}$. The characterisation of $4 \mathrm{~T} 1$ cells was performed by the quantification of the (E) area of tumoural clusters, which increased over time in single cultures, and (F) number of clusters, which decreased at $24 \mathrm{~h}$ in single culture. Data are given as means $\pm \operatorname{SEM}(n=3,10$ fields/condition). A one-way ANOVA was used to evaluate the significant differences within single and mixed cultures along time, represented by $\#$ 0.01 and ${ }^{\# \# \#} p<0.001$, and to evaluate the significant differences between single and mixed cultures at the same timepoint, represented by ${ }^{* *} p<0.01$ and ${ }^{* *} p<0.001$. A Mann-Whitney test was used to evaluate the significant differences between single and mixed cultures at $24 \mathrm{~h}$ of membrane $\beta$-catenin intensity, represented by $\$ \$ \$<0.001$.

The results showed that $\beta$-catenin is expressed by both b.End 5 and $4 \mathrm{~T} 1$ cells, in single and in mixed cultures (Figure 2A). They also revealed that BCCs led to a reorganization of the junctional protein expression at the membrane level in BMECs, as well as to an impairment of the elongated and aligned morphology, with b.End5 appearing to be more rounded (Figure 2A). Semi-quantitative analysis revealed that $\beta$-catenin expression in endothelial cultures increased at $24 \mathrm{~h}$ ( $p<0.001$ vs. 1, 3 and $6 \mathrm{~h}$, Figure 2B), in line with the SS-induced effect on the expression of the junctional protein (Figure 1B), while in mixed cultures, such an increase was not observed along time. Importantly, after $24 \mathrm{~h}, \beta$ catenin expression in b.End5 cells was significantly lower in mixed than in single cultures $(p<0.001$, Figure 2B). Such a decrease was accompanied by a reduction in membrane $\beta$-catenin ( $p<0.001$, Figure $2 \mathrm{C}$ ) and corroborated by the plot profile (Figure 2D), where almost no intensity is observed in the membrane of b.End5 cells in mixed cultures (dashed line) compared with single culture (solid line). Regarding 4T1 cells alone, they formed increasingly larger clusters (i.e., three or more 4T1 grouped cells) in single cultures along time (Figure 2E), whereas more clusters were observed in mixed cultures at $24 \mathrm{~h}(p<0.01$ vs. single culture, Figure $2 \mathrm{~F})$. Nevertheless, $\beta$-catenin, at both early $(1 \mathrm{~h})$ and later $(24 \mathrm{~h})$ timepoints, presented a similar distribution pattern in 4T1 cells in both single and mixed culture, localising mainly towards the cell membrane (Figure 2A).

Regarding TJ, we observed that both b.End5 and 4T1 express ZO-1 in single and mixed cultures (Figure 3). ZO-1 localised preferentially at the membrane level in single cultures of b.End5, whereas in mixed culture a progressive disorganisation of the ZO-1 labelling, with uneven and non-homogeneous staining at the cell membrane level and an unorganised endothelial monolayer, was observed (Figure 3A). An in-depth analysis of ZO-1 expression at $24 \mathrm{~h}$ revealed that this $\mathrm{TJ}$ is discontinuous along the cell membrane, corresponding to membrane gaps (Figure 3B). Accordingly, semi-quantitative analysis showed a significant increase in membrane gaps in b.End5 cells exposed to 4T1 cells $(p<0.001$, Figure $3 C)$. Importantly, after $24 \mathrm{~h}$ of contact with BCCs, the endothelium appeared disrupted, as confirmed by the presence of holes in the monolayer (Figure 3D). Regarding 4T1 cells, the distribution of ZO-1 presented a preferential localisation at the membrane level, though in mixed cultures it also appeared at the cytoplasm (Figure 3A).

Overall, these findings suggest that the interaction between the $4 \mathrm{~T} 1$ and $\mathrm{b}$.End5 cells compromises BBB endothelium integrity, affecting not only the AJs but also the TJs, pointing to a possible paracellular mechanism of tumour cells' TEM. 


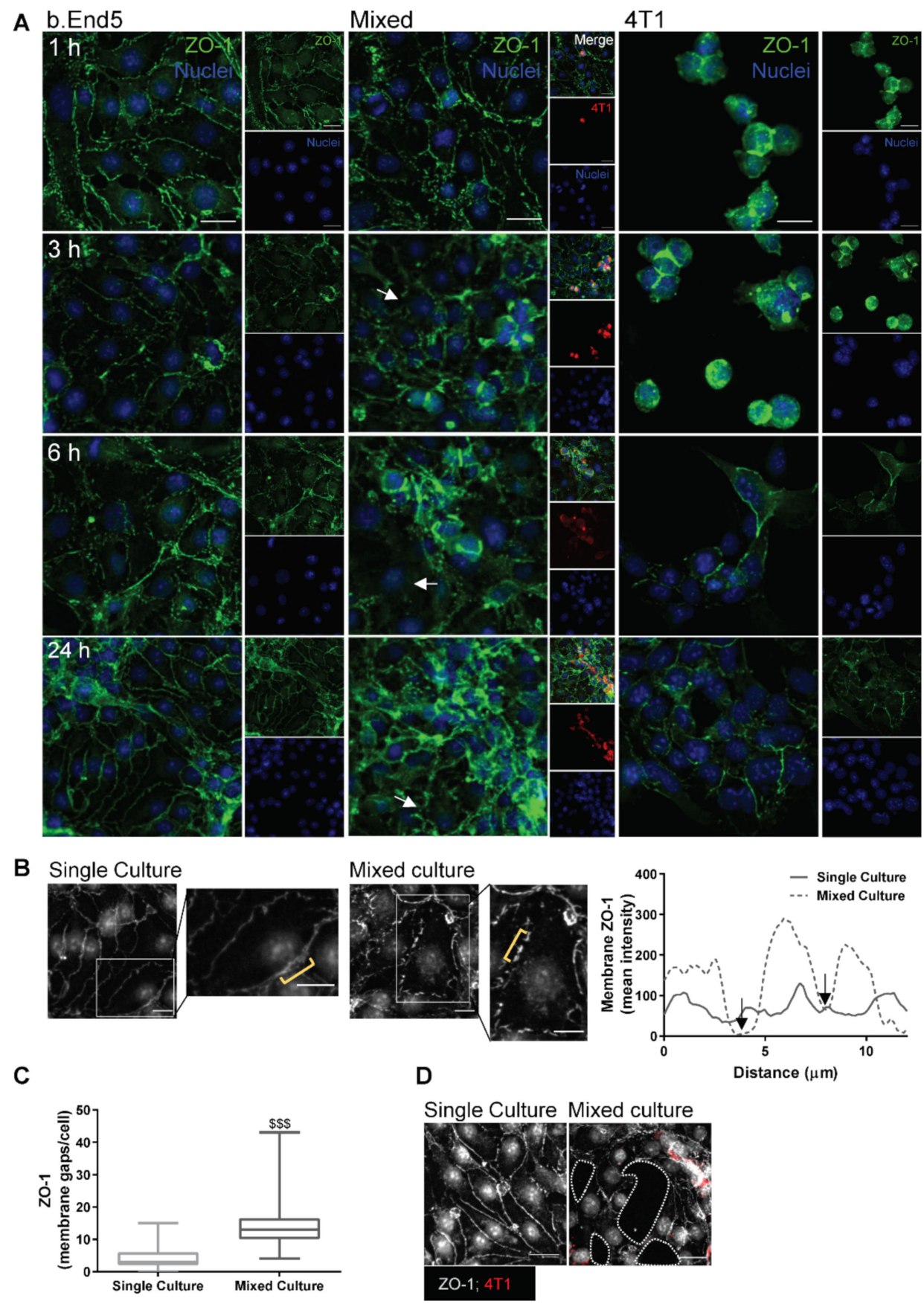

Figure 3. Tight junctions are compromised during interaction between breast cancer cells and brain microvascular endothelial cells. Confluent monolayers of the brain endothelioma cell line b.End5 under physiological laminar non-pulsatile shear stress were exposed to 4T1 breast cancer cells (previously labelled with CellTracker ${ }^{\mathrm{TM}}$ DMTPX Red Dye) for 1, 3, 6 and $24 \mathrm{~h}$ and the expression of the tight junction protein, zonula occludens-1 (ZO-1), in single and mixed cultures was evaluated by immunofluorescence analysis. (A) Analysis of the expression of ZO-1 (green) revealed that this protein is present in both cell types, with a different cellular distribution and disorganisation in b.End5 cells exposed to 4T1 cells (white arrows). Hoechst 33342 was used as counterstaining for nuclei (blue). Scale bar: $20 \mu \mathrm{m}$. (B) Analysis of membrane ZO-1 expression (grey) in b.End5 cells in mixed culture at $24 \mathrm{~h}$ revealed the presence of membrane gaps (insets and black arrows in the plot, which corresponds to the membrane region pointed out in yellow). Scale bar: $20 \mu \mathrm{m}$. (C) Semi-quantitative analysis revealed an increase in the number of membrane gaps in b.End5 cells in mixed cultures. (D) Inspection of the endothelial monolayer revealed holes (dotted lines) near 4T1 cells (red). Scale bar: $15 \mu \mathrm{m}$. Data are given as means \pm SEM ( $n=3$, 10 fields/condition). Mann-Whitney test was used to evaluate the significant differences of membrane gaps, represented by $\$ \$ p<0.001$. 


\subsection{BBB Transcellular Permeability Increases with BMEC-BCC Interaction}

Besides paracellular alterations observed regarding TJs and AJs, we further wanted to assess whether caveolae-mediated transcytosis is upregulated upon b.End5 exposure to $4 \mathrm{~T} 1$ cells. To this end, the expression of the major protein constituent of caveolae, cav-1 [29], was examined (Figure 4).

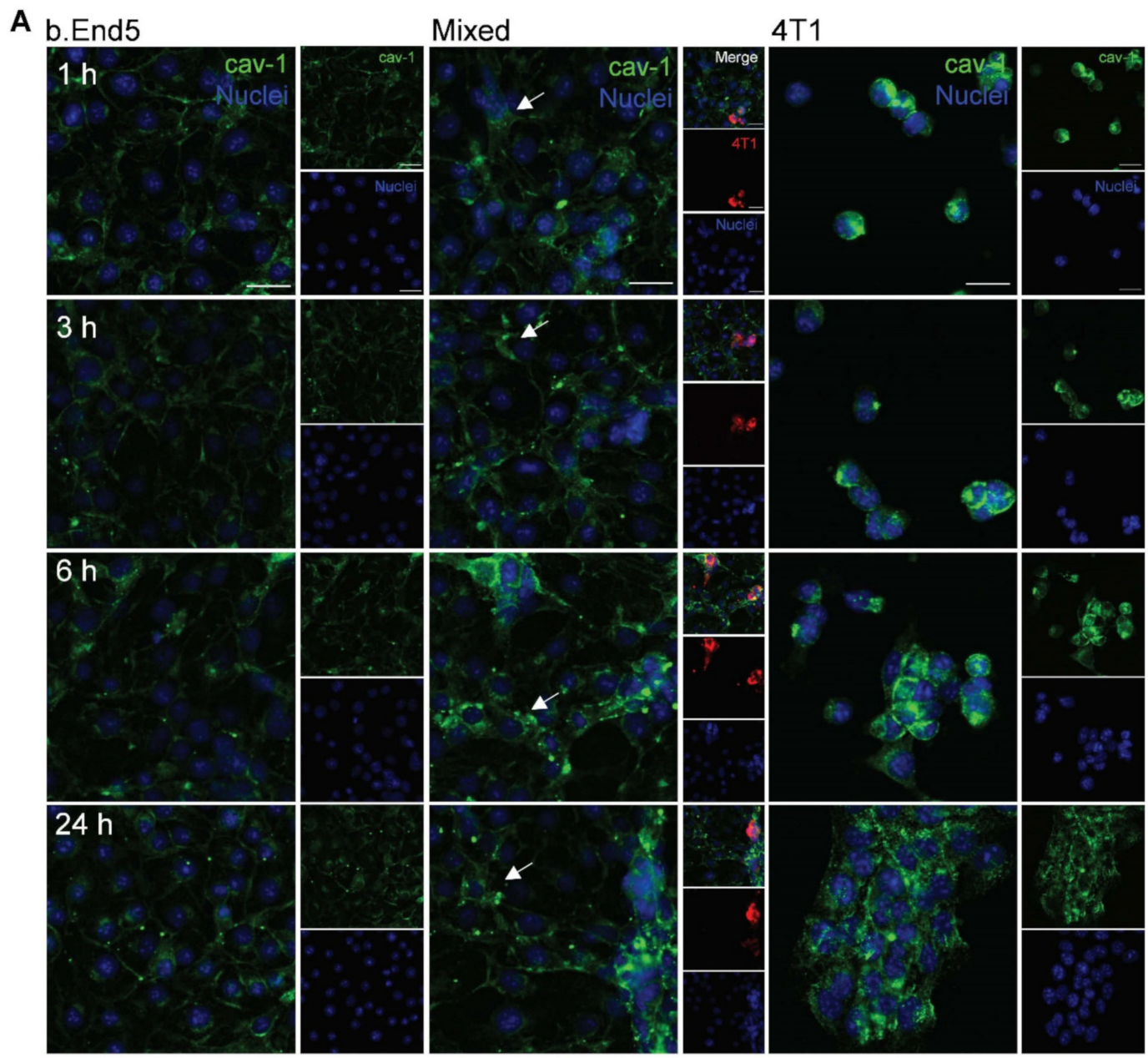

B

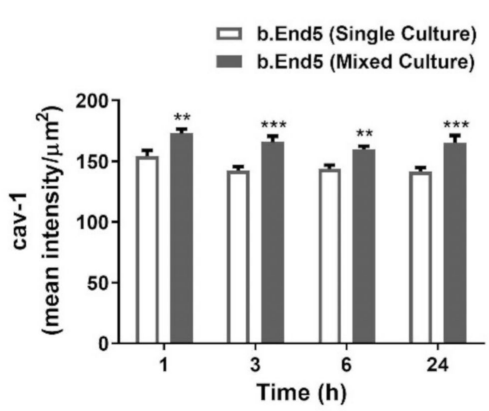

C

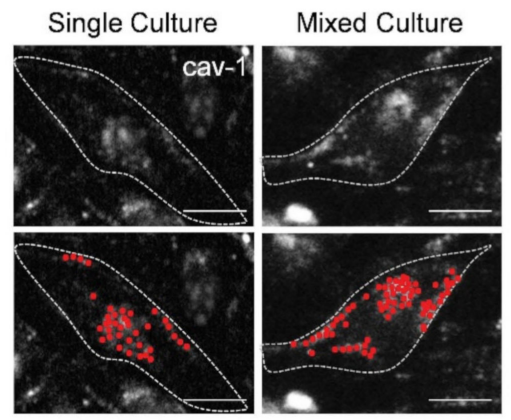

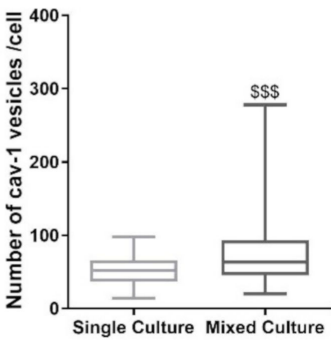

Figure 4. Vesicular trafficking alterations occur during breast cancer cell and brain microvascular endothelial cell interaction. Confluent monolayers of the brain endothelioma cell line b.End5 under physiological laminar non-pulsatile shear stress were exposed to $4 \mathrm{~T} 1$ breast cancer cells (previously labelled with CellTracker ${ }^{\mathrm{TM}}$ DMTPX Red Dye) for 1, 3, 6 and $24 \mathrm{~h}$ and the expression of the main protein of caveolae, caveolin-1 (cav-1), in single and mixed cultures was evaluated by immunofluorescence analysis. (A) Analysis of the expression of cav-1 (green) revealed that the vesicular trafficking protein is present in both cell types, with a different cellular distribution and disorganisation in b.End5 cells (white arrows) exposed 
to $4 \mathrm{~T} 1$ cells. Hoechst 33342 was used as counterstaining for nuclei (blue). Scale bar: $20 \mu \mathrm{m}$. (B) Semi-quantitative analysis revealed an increase in endothelial cav-1 intensity in mixed cultures vs. single culture. (C) Cav-1-positive vesicles were analysed in b.End5 cells in single and in mixed cultures at $24 \mathrm{~h}$ and representative images of the original and algorithm-based detected spots (red) are shown (up and down images, respectively); semi-quantitative analysis revealed an increase in the number of vesicles in mixed cultures as compared with single cultures. Scale bar: $10 \mu \mathrm{m}$. Data are given as means \pm SEM $(n$ $=3,10$ fields/condition). A one-way ANOVA was used to evaluate the significant differences between single and mixed cultures at the same timepoints, represented by ${ }^{* *} p<0.01$ and ${ }^{* * *} p<0.001$. A Mann-Whitney test was used to evaluate the significant differences of the number of caveolae at $24 \mathrm{~h}$ represented by $\$ \$ \$<0.001$.

We observed that cav-1 is expressed in both b.End5 and 4T1 cells (Figure 4A). Cav-1 in b.End5 cells was mainly observed at the membrane level in single culture, while in mixed cultures the expression of the vesicular protein in the cytosol was observed, in line with the occurrence of caveolae-mediated transcytosis. Semi-quantitative analysis revealed an increase in cav- 1 in b.End5 cells in mixed cultures comparatively to single cultures in all timepoints ( $p<0.01$ at 1 and 6 h; $p<0.001$ at 3 and 24 h, Figure $4 B$ ). Spot analysis of cav-1-positive vesicles at $24 \mathrm{~h}$ reinforced such observations, demonstrating an increase in the number of cav-1-positive vesicles in b.End5 cells when exposed to 4T1 cells $(p<0.001$, Figure 4C).

These results point to the association between transcellular hyperpermeability (via an increase in cav-1 expression and caveolae number) and $4 \mathrm{~T} 1$ cells' transmigration across the BBB. Moreover, they reveal that cav-1 is expressed in "metastasis-like" clusters, in line with a pro-tumourigenic effect of the caveolae-associated protein.

\subsection{The GJs Protein Cx43 Is Involved in BMECs-BCCs Interaction}

Considering that GJ intercellular communication has been considered a key mechanism in tumour cells' migration and proliferation [36], the analysis of Cx43 during BCC and BMEC interaction was performed (Figure 5).

Our results revealed that both b.End5 and 4T1 in single and mixed cultures express Cx43, with specific patterns for each cell type in single and mixed cultures (Figure 5A). In endothelial cultures, $\mathrm{Cx} 43$ localised particularly in the perinuclear region, rather than at cell-to-cell contacts. After exposure to 4T1 cells, the perinuclear localisation was maintained but a redistribution throughout the cell was observed. Moreover, location of the protein in endothelial-tumour cell contact regions was detected. In single cultures of 4T1 cells, Cx43 was initially located in the perinuclear region ( 1 and $3 \mathrm{~h}$ ), extending to the cytosol $(6 \mathrm{~h})$ and afterwards to cell-to-cell contacts ( $24 \mathrm{~h}$ ), as clusters developed (Figure 5B). A similar profile is observed in $4 \mathrm{~T} 1$ after contact with the endothelium, with the expression of $\mathrm{Cx} 43$ in tumour cell-to-cell contact later in time noticed (6 and $24 \mathrm{~h}$, Figure 5B).

These data suggest that $\mathrm{C} \times 43$ is involved in the interaction between endothelial and tumour cells, as well as among tumour cells during the formation of tumour clusters. 
A

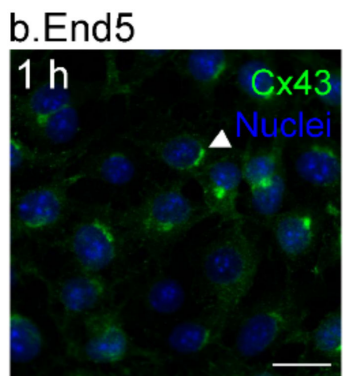

Mixed

4T1
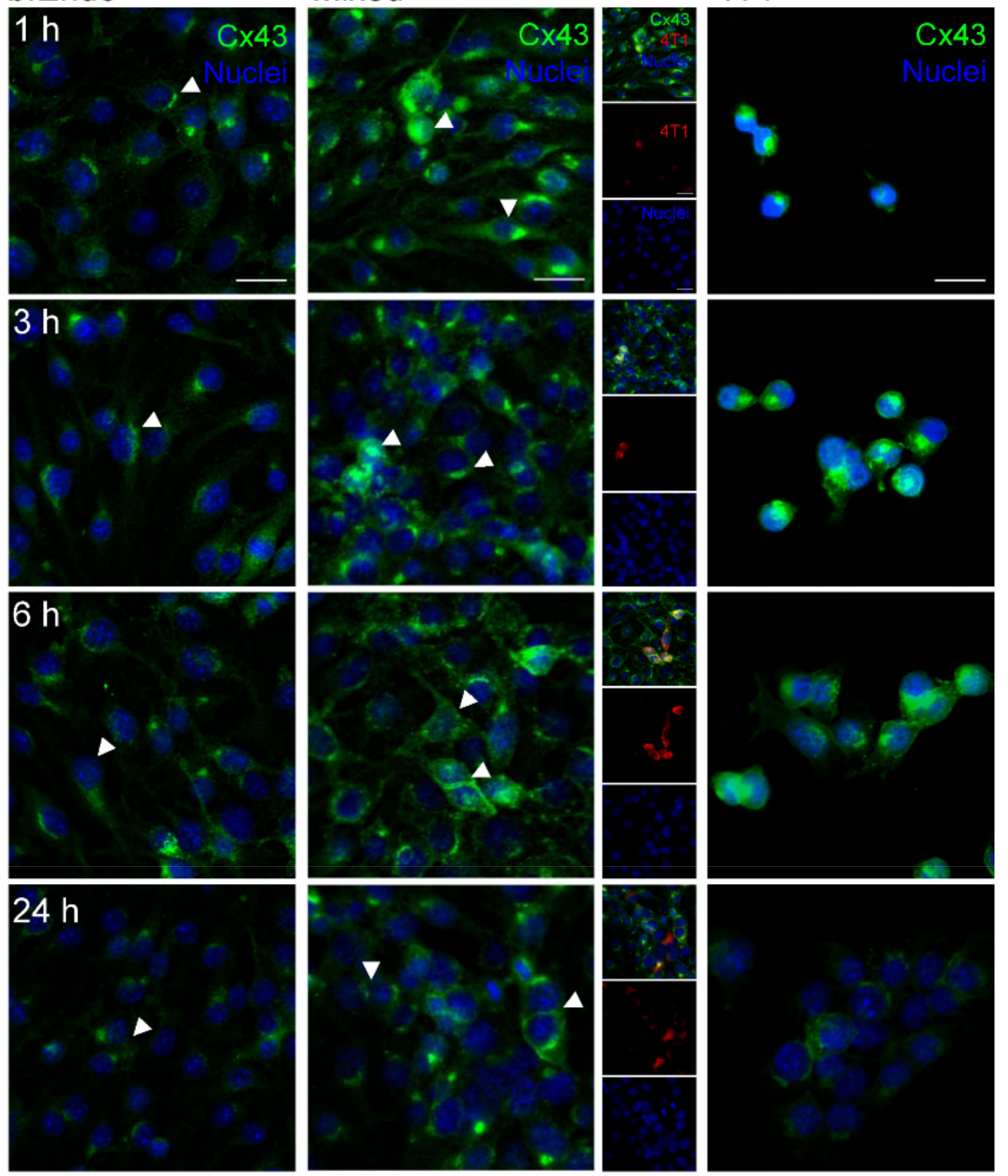

B

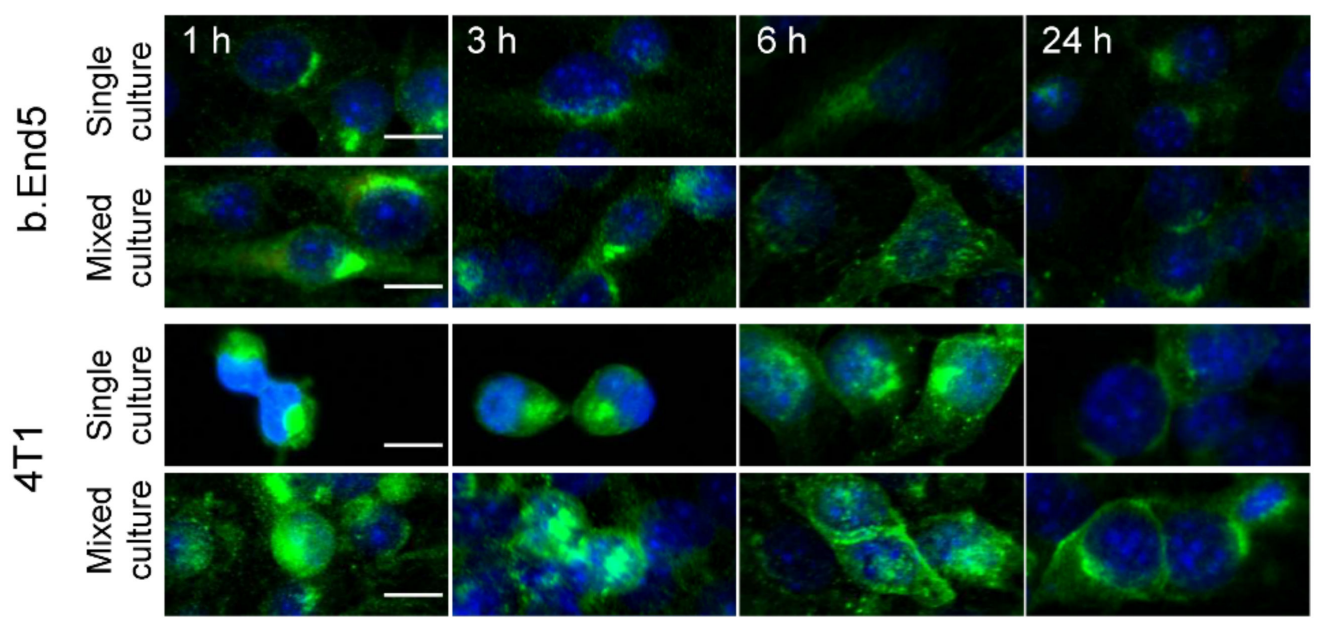

Figure 5. Alterations in the expression pattern of the gap junction protein connexin 43 (Cx43) occur during interaction between breast cancer cells and brain microvascular endothelial cells. Confluent monolayers of the brain endothelioma cell line b.End5 under physiological laminar non-pulsatile shear stress were exposed to 4T1 cells (previously labelled with CellTracker ${ }^{\mathrm{TM}}$ DMTPX Red Dye) for 1, 3, 6 and $24 \mathrm{~h}$, and the expression of Cx43 in single and mixed cultures was evaluated by immunofluorescence analysis. (A) Analysis of the expression of Cx43 (green) revealed that this gap junction protein is present in both cell types. Hoechst 33342 was used as counterstaining for nuclei (blue). Scale bar: $20 \mu \mathrm{m}$. cell type is shown 
with a greater magnification (indicated by arrow heads in panel A) to better elucidate the differences observed in Cx43 expression and localisation in single and mixed cultures. Scale bar: $5 \mu \mathrm{m}$.

\subsection{BMEC-BCC Interaction Leads to Cytoskeleton Alterations}

To investigate the association of endothelial cytoskeleton rearrangements with BCCs' transmigration, a cytoskeleton-associated protein, MLCK, reported to be involved in the transcellular intravasation of BCCs [28] and brain microvasculature hyperpermeability [40], was evaluated (Figure 6).

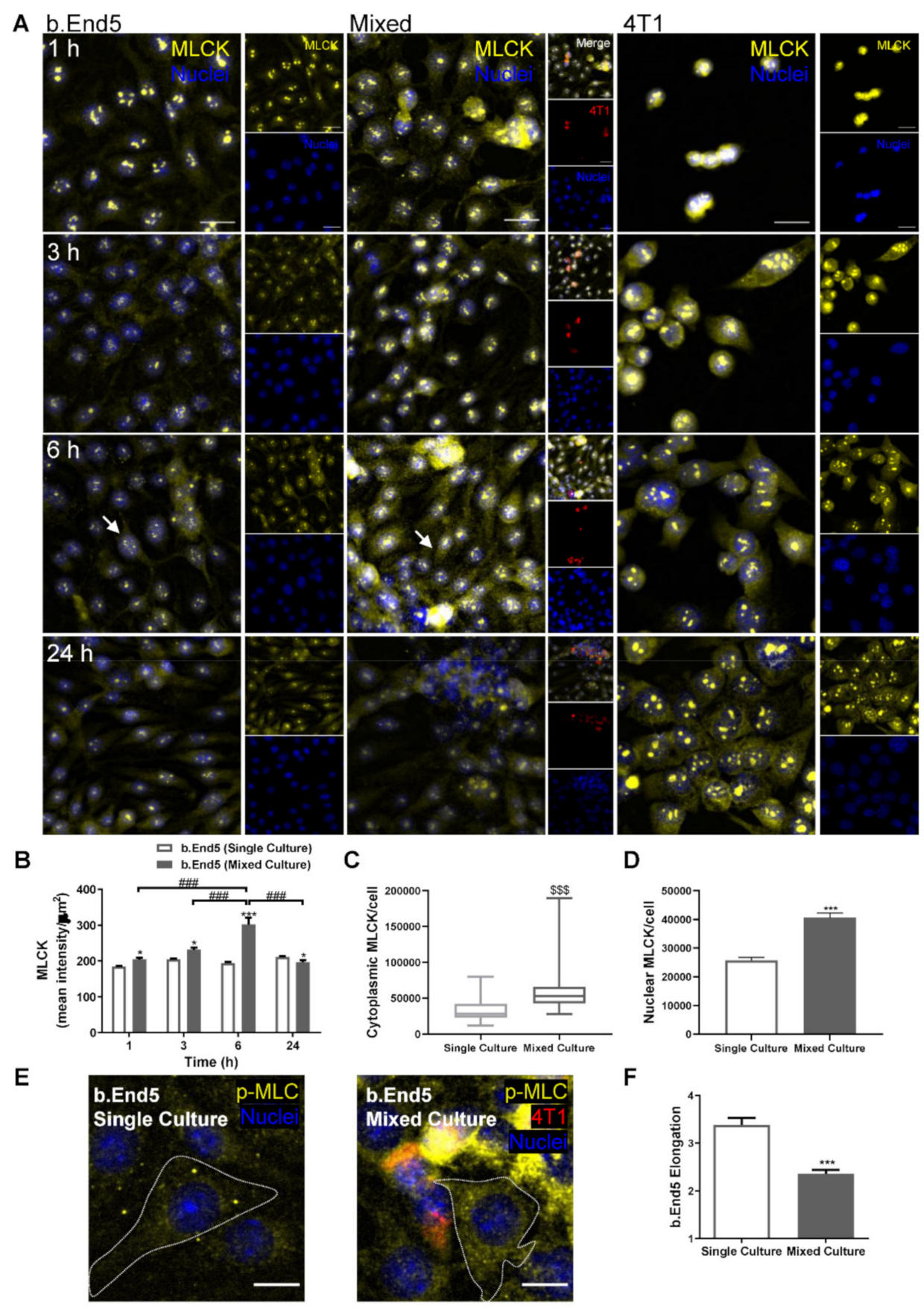

Figure 6. Interaction between breast cancer cells and brain microvascular endothelial cells leads to cytoskeleton rearrangement. Confluent monolayers of the brain endothelioma cell line b.End5 under physiological laminar non-pulsatile shear stress were exposed to 4T1 breast cancer cells (previously labelled with CellTracker ${ }^{\mathrm{TM}}$ DMTPX Red Dye) for 1, 3, 6 and $24 \mathrm{~h}$ and the expression of myosin light chain kinase (MLCK), as well as of phosphorylated myosin light chain (p-MLC), in single 
and mixed cultures was evaluated by immunofluorescence analysis. (A) Analysis of the expression of MLCK (yellow) revealed that the cytoskeleton-associated protein is present in both cell types, with a marked overexpression in b.End5 cells exposed to $4 \mathrm{~T} 1$ cells at $6 \mathrm{~h}$ (as shown by the white arrows). Hoechst 33342 was used as counterstaining for nuclei (blue). Scale bar: $20 \mu \mathrm{m}$. (B) Semi-quantitative analysis revealed an increase in endothelial MLCK intensity in mixed cultures, particularly at $6 \mathrm{~h}$. A significant increase in (C) cytoplasmic and (D) nuclear MLCK in mixed cultures compared with single ones was observed. (E) Cytoskeleton rearrangements were confirmed by the increase in p-MLC (yellow) observed in the cytoplasm of b.End5 cells (circumscribed by dotted line) exposed to $4 \mathrm{~T} 1$ cells at $6 \mathrm{~h}$. Hoechst 33342 was used as counterstaining for nuclei (blue). Scale bar: $10 \mu \mathrm{m}$. (F) Semi-quantitative analysis of the morphology of p-MLC stained b.End5 revealed a decrease in elongation upon incubation with $4 \mathrm{~T} 1$ cells for $6 \mathrm{~h}$. Data are given as means $\pm \mathrm{SEM}(n=3$, 10 fields/condition). A one-way ANOVA was used to evaluate the significant differences within single and mixed cultures along time, represented by \#\#\# $p<0.001$, and to evaluate the significant differences between single and mixed cultures at the same timepoints, represented by $p<0.05$ and ${ }^{* *} p<0.001$. A Mann-Whitney test was employed to evaluate the significant differences in cytoplasmic intensity, represented by $\$ \$ \$<0.001$. A two-tailed Student's $t$-test was used to evaluate the significant differences in nuclear intensity and cell elongation, represented by ${ }^{* * *} p<0.001$.

Both endothelial and tumour cells expressed MLCK, in single and mixed cultures, being evident at the cytoplasmatic level and in nuclear foci, as well as a marked overexpression in ECs in mixed cultures at $6 \mathrm{~h}$ of interaction (Figure 6A). Semi-quantitative MLCK fluorescence intensity analysis revealed that it was kept constant in b.End5 single cultures over time, whereas in mixed cultures an increase was observed, particularly notorious at $6 \mathrm{~h}(p<0.001$ vs. 1,3 and $24 \mathrm{~h}$ ), also being significantly higher compared to its expression in single culture at the same timepoint $(p<0.001$, Figure $6 \mathrm{~B})$. Interestingly, the observed increase in the mean intensity appears to be mainly due to the cytoplasmatic MLCK overexpression $(p<0.001$, Figure 6C), even though an increase in nuclei foci was also observed $(p<0.001$, Figure $6 \mathrm{D})$. Such an observation was corroborated by the increase in p-MLC cytoplasmatic intensity in mixed cultures (Figure 6E). Additionally, morphologic alterations were observed in b.End5 cells in mixed culture, with a decreased elongation of BMECs $(p<0.001$; Figure $6 \mathrm{~F})$, supporting MLCK's effect on cell contractility.

These results reinforce the occurrence of cytoskeleton alterations as a consequence of BCCs' interaction with BMECs.

\subsection{Adhesion-Related Signaling Pathway Activation Occurs during BMEC-BCC Interaction}

In order to disclose adhesion signalling involvement in $\mathrm{BCCs}^{\prime}$ interaction with the BBB endothelium, the expression of known adhesion-associated proteins, namely FAK [41] and $\beta 4$-integrin [42], was evaluated (Figure 7).

Our results demonstrated that b.End5 and $4 \mathrm{~T} 1$ cells expressed FAK and $\beta 4$-integrin, both in single and mixed culture, presenting different expression and localisation patterns regarding cell type and culture conditions. In fact, FAK localisation changed from the membrane in b.End5 cultures towards the cytoplasm in b.End5 cells exposed to $4 \mathrm{~T} 1$ cells. Moreover, a marked decrease in endothelial FAK expression was observed in $24 \mathrm{~h}$ mixed cultures, reflecting an impairment of the endothelial monolayer. The protein expression in 4T1 was mainly located in the perinuclear region, though some cytoplasm distribution was observed as well, both in single and in mixed cultures (Figure 7A). The subcellular localisation of FAK was corroborated by the plot profile analysis, which depicted a preferential location in the membrane and some perinuclear expression in b.End5 single cultures, which disappeared in mixed culture at $24 \mathrm{~h}$ (green filled line in the plots, Figure 7B). 


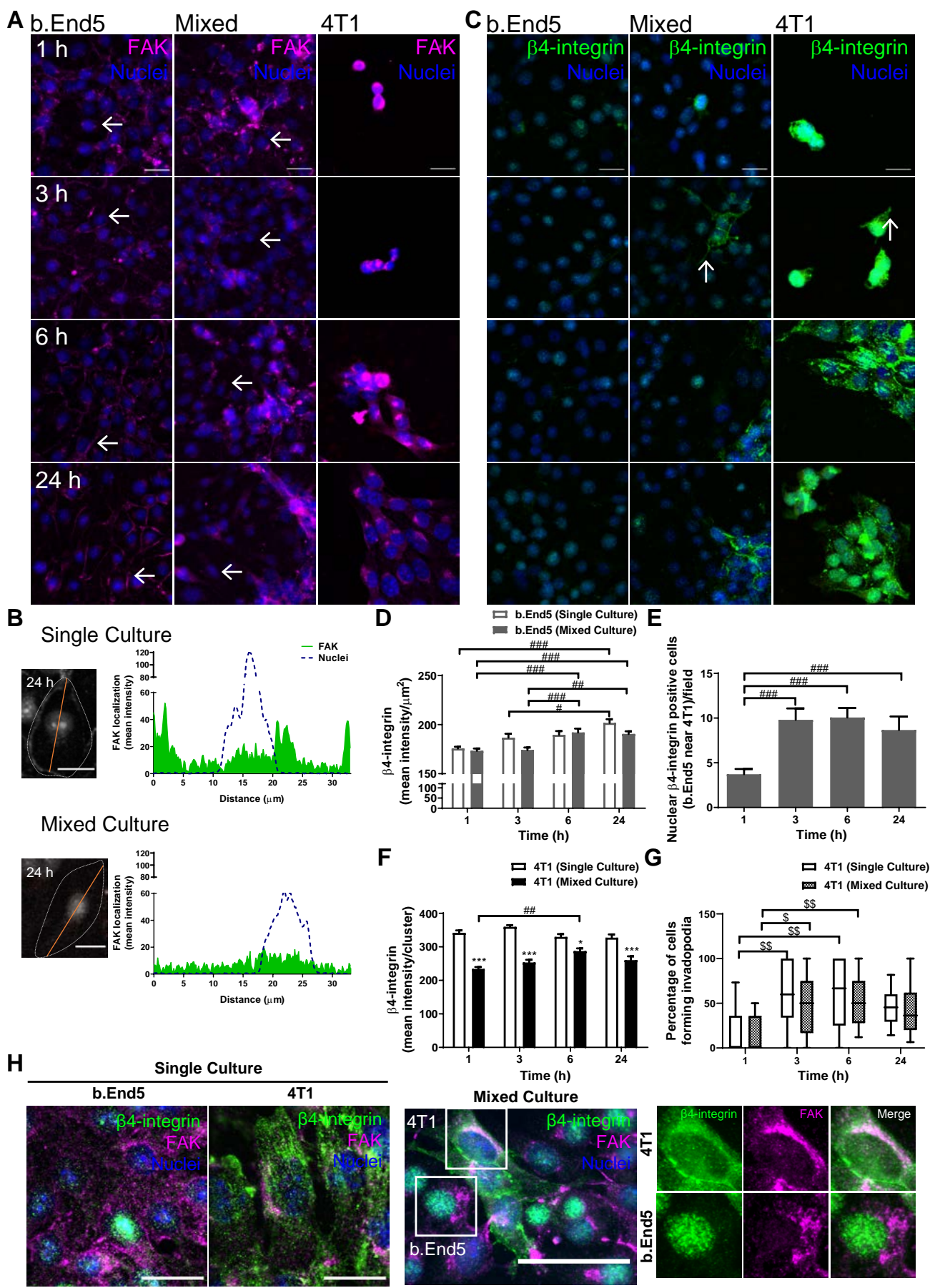

Figure 7. Interaction between breast cancer cells and brain microvascular endothelial cells leads to activation of adhesionrelated signalling pathways. Confluent monolayers of the brain endothelioma cell line b.End5 under physiological laminar non-pulsatile shear stress were exposed to $4 \mathrm{~T} 1$ breast cancer cells (previously labelled with CellTracker ${ }^{\mathrm{TM}}$ DMTPX Red Dye) for 1, 3, 6 and $24 \mathrm{~h}$ and the expression of focal adhesion kinase (FAK) and $\beta 4$-integrin in single and mixed cultures was evaluated by immunofluorescence analysis. (A) Analysis of the expression of FAK (purple) revealed that the protein is present in both cell types, with an early overexpression, followed by a decrease in b.End5 cells exposed to $4 \mathrm{~T} 1$ cells (white arrows). (B) Plot profiles showed notorious alterations in FAK (grey, cell border identified as dotted grey line) cell localisation and decreased expression in b.End5 in mixed culture as compared with single culture at $24 \mathrm{~h}$. (C) Analysis of the expression of $\beta 4$-integrin (green) showed that the protein is expressed in both cell types, with no changes in mixed cultures, and highlighted invadopodia formation in $4 \mathrm{~T} 1$ cells in both single and mixed culture (white arrows). Hoechst 33342 was used as counterstaining for nuclei (blue). Scale bar: $20 \mu \mathrm{m}$. (D) Semi-quantitative analysis of $\beta 4$-integrin expression revealed an increased content in b.End5 in single and mixed cultures along time. (E) Nuclear $\beta 4$-integrin-positive b.End5 cells in close 
vicinity to $4 \mathrm{~T} 1$ increased along time. (F) Semi-quantitative analysis of $\beta 4$-integrin intensity per $4 \mathrm{~T} 1$ clusters revealed a decrease in mixed cultures as compared with single ones. (G) Quantitative analysis of the number of 4T1 cells forming invadopodia revealed an increase post $3 \mathrm{~h}$ of culture in both single and mixed culture. $(\mathbf{H})$ Double-labelling with $\beta 4$-integrin and FAK depicted a notorious difference in the proteins' cellular distribution in b.End5 and 4 T1 cells both in single and mixed culture, shown by the colocalisation analysis revealing that both proteins colocalise in $4 \mathrm{~T} 1$ cells (white coloration). Hoechst 33342 was used as counterstaining for nuclei (blue). Scale bar: $20 \mu \mathrm{m}$. Data are given as means \pm SEM ( $n=3$, 10 fields/condition). One-way ANOVA was used to evaluate the significant differences within single and mixed cultures along time, represented by ${ }^{\#} p<0.05,{ }^{\# \#} p<0.01$ and ${ }^{\# \#} p<0.001$, and to evaluate the significant differences between single and mixed cultures at the same timepoints, represented by ${ }^{*} p<0.05$ and ${ }^{* * *} p<0.001$. A Kruskal-Wallis test was used to evaluate the significant differences in the percentage of $4 \mathrm{~T} 1$ cells forming invadopodia in single and mixed cultures along time, represented by $\$ p<0.05$ and $\$ \$ p<0.01$. A two-tailed Student's $t$-test was used to evaluate the significant differences along time in b.End5 cells in mixed cultures with increased nuclear $\beta 4$-integrin, represented by ${ }^{\# \#} p<0.01$ and ${ }^{\# \#} p<0.001$.

As far as $\beta 4$-integrin is concerned, its localisation in b.End5 cells appeared similar in both cultures, while in $4 \mathrm{~T} 1$ cells its localisation changed along time, becoming more membrane/cytoplasmatic from $3 \mathrm{~h}$ onwards, particularly in mixed culture (Figure 7C). Additionally, the $\beta 4$-integrin-positive membrane protrusions formed by $4 \mathrm{~T} 1$ were noticeable as early as $3 \mathrm{~h}$, in single and mixed culture (Figure $7 \mathrm{C}$ ). Semi-quantitative analysis of $\beta 4$-integrin labelling intensity (Figure 7D) revealed an increase along time in single culture $(p<0.001$ at $24 \mathrm{~h}$ vs. $1 \mathrm{~h} ; p<0.05$ at $24 \mathrm{~h}$ vs. $3 \mathrm{~h}$ ), as well as in mixed culture $(p<0.001$ at $6 \mathrm{~h}$ vs. 1 and $3 \mathrm{~h} ; p<0.001$ at $24 \mathrm{~h}$ vs. 1 and $3 \mathrm{~h}$ ), with no alterations in mixed versus single cultures, suggesting that the observed increase was a reflex of SS. It is important to mention that, in mixed cultures, $\beta 4$-integrin nuclear expression in $b$.End 5 cells in close proximity to $4 \mathrm{~T} 1$ clusters appeared to be more intense (Figure $7 \mathrm{C}$ ). This was corroborated by the semi-quantitative analysis of b.End5 cells with nuclear $\beta 4$-integrin (Figure 7E), which highlighted an increase at $3 \mathrm{~h}(p<0.001$ vs. $1 \mathrm{~h})$, sustained afterwards $(p<0.001$ at $6 \mathrm{~h}$ vs. $1 \mathrm{~h} ; p<0.01$ at $24 \mathrm{~h}$ vs. $1 \mathrm{~h}$ ). Semi-quantitative analysis of $\beta 4$-integrin in $4 \mathrm{~T} 1$ cells revealed a general decrease in the mean intensity per cluster in mixed as compared with single cultures $(p<0.001$, Figure 7F). Quantitative analysis of the number of 4 T1 cells forming invadopodia (Figure 7G) revealed an increase from $3 \mathrm{~h}$ of single culture $(p<0.01$ at $1 \mathrm{~h}$ vs. 3 and $6 \mathrm{~h}$ ) as well as in mixed culture ( $p<0.05$ at $3 \mathrm{~h}$ vs. $1 \mathrm{~h} ; p<0.01$ at $6 \mathrm{~h}$ vs. $1 \mathrm{~h}$ ).

It is known that, in tumour cells, FAK and $\beta 4$-integrin interact, prompting cell migration and invasiveness [13]. Thus, we performed a double-labelling of FAK and $\beta 4$-integrin. As shown in Figure 7H, FAK and $\beta 4$-integrin are co-expressed in the perinuclear region of 4T1 cells in single and particularly in mixed cultures, in contrast with b.End5 cells that exhibit a distinct location of each protein, with the former in the perinuclear region and the latter in the nuclei. These observations attest the proximity of both proteins in malignant cells, in line with the important role of their interaction in tumourigenesis.

Our data suggest that both FAK and $\beta 4$-integrin are involved in the processes of $4 \mathrm{~T} 1$ interaction with the BBB endothelium.

\section{Discussion}

Despite the fact that BCCs' intravasation mechanisms are well established [43], BCCs extravasation is a process that is not yet fully comprehended, in particular regarding TEM and the players involved. Tumour cells' TEM across the BBB has been described to occur either by the paracellular route [22] or by the transcellular one [23], but the exact mechanisms and intervenients in BCCs' extravasation are not yet fully disclosed. A recent study by our team provided comprehensive evidence regarding in vivo $\mathrm{BC}$ brain metastasis formation hallmarks [19]. In the present work, we further disclosed players and mechanisms involved, highlighting the role of AJs, TJs, GJs, caveolae, the cytoskeleton, kinases, and adhesion proteins along in vitro BCCs' interaction with BMECs, pointing to their hub role along extravasation (schematically depicted in Figure 8), mirroring most of the in vivo observations [19]. 


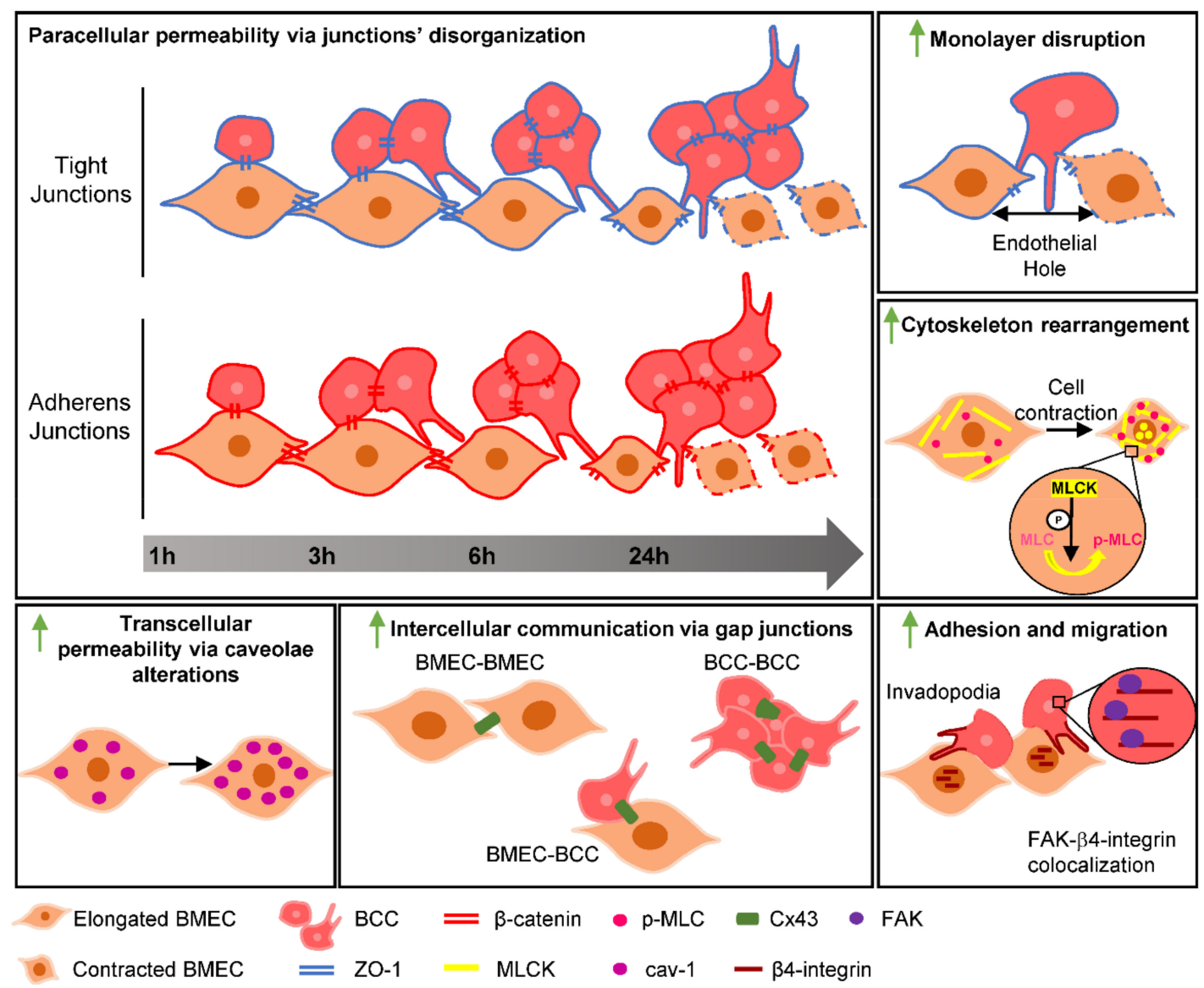

Figure 8. Schematic representation of the players involved in the interaction between brain microvascular endothelial cells (BMECs) and breast cancer cells (BCCs). Along time, BCCs form clusters that increase in size. BMECs, upon contact with BCCs, suffer several alterations, where junctional impairment, indicated by $\beta$-catenin and zonula occludens (ZO)-1, and endothelial monolayer hole formation are noticeable at later timepoints. Additionally, cytoskeleton rearrangements occur through an increase in myosin light chain kinase (MLCK) and phosphorylated myosin light chain (p-MLC), resulting in BMEC contraction and transcytosis upregulation shown by the increase in the vesicular content of caveolin-1 (cav-1), supporting endothelial paracellular and transcellular hyperpermeability involvement in BCCs' transmigration. BCCs present migratory properties seen by the formation of invadopodia. The expression alterations in connexin 43 (Cx43) suggest that this gap junction protein is involved in the interaction between BMECs and BCCs. $\beta 4$-Integrin in invadopodium and $\beta 4$-integrin-focal adhesion kinase (FAK) colocalisation point to their role in intercellular adhesion and BCC migration.

A novel cellular system replicating BCCs' interaction with BBB endothelial cells during the process of the extravasation of malignant cells into the brain was developed. This in vitro model encompasses b.End5 monolayers, mimicking the BBB, cultured under orbital rotation to recapitulate physiological SS in mixed cultures with highly metastatic triplenegative BCCs, 4 T1 cells, fluorescently labelled to distinguish individual cell types. As a result of the mechanical stimulus, BMEC cultures present an in vivo-like morphology, becoming more elongated and aligned, increasing the expression of junctional proteins, in line with previous observations by our group [17]. In this system, 4T1 cells appear to behave differently comparatively with single culture, where "metastasis-like" clusters are formed on top of the endothelial monolayer, which increase in size along time. Although it is known that the major cause of tumour cell loss during the metastatic process is the circulation in the bloodstream [44], mimicked by SS in our system, cluster formation seems to be an adaptive response of 4T1 to better survive, adhere and invade the endothelium. In fact, cluster formation was already described to occur in vivo, as a defence mechanism of BCCs, facilitating the metastatic process [45]. Contrarily to single migration, the association of cluster formation with the collective migration of tumour cells that seems to be a way 
of saving energy. In these clusters, the so called "leader cells" are generally located at the periphery, being responsible for the guidance of cluster migration and tending to be more aggressive $[46,47]$. Moreover, this type of migration seems to rely on the formation of membrane protrusions in the leader cells at the cluster's front [48]. Indeed, we observed that cells at the cluster's periphery are the ones that present some footlike projections, such as invadopodia, known to be associated with tumour cell migration, suggesting that collective migration is a mechanism acquired by $4 \mathrm{~T} 1$ cells to be able to migrate and invade the BBB. Although collective migration has been described for the intravasation of BCCs [49], as well as in studies of BCCs' extravasation through ECs in microfluidic devices [50], the present results suggest that collective migration may also be associated with TEM of BCCs across BMECs. This suggestion is supported by a previous work showing that cell-cell junctions are important for aggregate/cluster cohesion [51], and the present results showing that $4 \mathrm{~T} 1$ cells express the junctional proteins, $\beta$-catenin and ZO-1.

It is known that both $\mathrm{TJ}$ and $\mathrm{AJ}$ proteins play a crucial role in BBB tightness and selective permeability maintenance [16]. However, the disruption of junctional complexes in the context of brain metastasis formation has been reported [52,53], leading to an increase in brain permeation, a phenomenon that has also been associated with BCCs' paracellular transmigration [19]. Indeed, a decrease in the TJ and AJ proteins, claudin- 5 and $\beta$-catenin, respectively, was observed along the formation of 4T1-derived metastasis in vivo, with a concomitant increase in the BBB permeability shown by thrombin infiltration into the brain parenchyma, particularly in advanced stages of metastases development [19]. In line with these features observed in a mouse model, the present in vitro studies revealed that $b$.End5 cells present a decrease in $\beta$-catenin and ZO-1 expression at the plasma membrane, where the ZO-1 staining disclosed the presence of membrane gaps and the presence of holes in the endothelial monolayer. Interestingly, endothelium disruption depends on both endothelial and tumour cells. In the case of interaction between mice endothelioma cell line, b.End3, and the BCC line, MDA-MB-231, for 4-8 h, both adherent and transmigrated BCCs were observed, with endothelial TJ impairment in contact regions due to the partial and total disruption of membrane ZO-1, respectively [54]. On the other hand, in melanoma cells, a disruption of EC-EC junctions is observed early in time post-endothelial-tumour cell contact with the increase in holes in the endothelium near the tumour cells [55]. Similarly, in our study, endothelial disruption in the vicinity of BCCs occurs, although later in time compared with both studies. Due to the alterations observed at the endothelial level, we can point to a likely paracellular mechanism of BCCs' transposition of the BBB.

Although the present results indicate that the paracellular route is affected by b.End54T1 interaction, the transcellular pathway cannot be discarded. This pathway has been recognised for leucocytes' TEM, namely across the BBB, with the involvement of cytoskeleton remodelling, pore formation within ECs, and protrusion extension of leukocytes [56], as well as in BC brain metastasis formation [23]. Among the proteins described to have a role in the transcellular pathway and endothelial permeability, cav-1 is a key player $[30,57]$. Cav-1 is the main protein constituent of caveolae [16], which are believed to function not only as vesicular transporters, but also as a signal platform that regulates cell proliferation, differentiation, and metastases development $[58,59]$. The increase in cav- 1 has been associated with endothelial hyperpermeability, particularly at the BBB, being an early event compared with TJ impairment $[57,60]$. Our results showed an increase in cav-1 expression in BMECs in mixed cultures compared with single ones, as well as a significant increase in the caveolae number later in time, coincident with junctional disruption. Consistently, cav-1 upregulation was also observed in in vivo $\mathrm{BC}$ brain metastasis formation, particularly in blood vessels in the vicinity of BCCs and of metastatic brain lesions [19]. The parallelism between the findings attained in the present study and the ones obtained in vivo reinforces the physiological relevance of our in vitro model for mirroring the in vivo disease pathobiology.

Endothelial cytoskeleton rearrangements have been correlated with cancer cell transmigration, being particularly described during intravasation through vascular ECs, where 
an endothelial actomyosin circumferential pore is formed, regulated by MLCK phosphorylation of MLC and prompting cytoskeleton rearrangements and actin fibre formation [28,61]. For extravasation, the preference of BCCs for transcellular migration across BMECs has recently been shown, occurring by diapedesis through ECs' body [23]. Although the authors do not explore the mechanism, they propose the further study of cytoskeleton rearrangement involvement [23]. In conformity, our results demonstrate an increase in endothelial MLCK after $6 \mathrm{~h}$ of exposure to BCCs, with a concomitant increase in p-MLC, implying that cytoskeleton rearrangements are occurring in BMECs in response to BCCs, with possible association with transcellular transmigration. Interestingly, a decrease in the TJ protein ZO-1 following actin remodelling through MLC phosphorylation 4-8 h post BMEC-tumour cell contact, associated with junctional opening, was reported [53]. These observations corroborate our own of a ZO-1 decrease after MLCK overexpression and MLC phosphorylation in BMECs, suggesting that cytoskeleton rearrangements are associated with endothelial junctional opening during BCCs' TEM. Additionally, we highlight the observation of MLCK nuclear foci, particularly in BMECs, which decreased in contact with BCCs. Nuclear MLCK was related to the dynamics of the nuclear cytoskeleton and the regulation of gene transcription in human colonic smooth muscle cells [62], whereas nuclear myosin seems to be involved in nuclear actin shifting and compaction associated with the migration and TEM of BCCs during intravasation [63]. Our present results are in line with those conclusions, once alterations in endothelial MLCK and p-MLC upon contact with BCCs point to cytoskeleton alterations, which enhance BCC transmigration associated with an increase in BMEC permeability. Altogether, our results support the involvement of MLCK and cav-1 in the endothelium hyperpermeability and BCCs' transcellular migration.

The role of GJs in intercellular communication in numerous physiological cellular functions, especially in proliferation control, accounts for the growing attention in the field of oncology [34], either between tumour cells in a metastatic environment, or even the crosstalk that can be established between BMECs and BCCs [64]. The relevance of Cx43 for the extravasation process of BCCs was previously demonstrated both in pulmonary [65] and in brain endothelium, where the inhibition of this GJ protein was associated with metastases formation inhibition [64]. Consistent with these findings, overexpressed Cx43 in BCCs promoted cell migration [66]. Here, we demonstrated that $C \times 43$ is expressed by BMECs and BCCs and undergoes a subcellular redistribution upon interaction, pointing to a possible role of this protein in the interaction between the two cell populations. An increase in Cx43 expression was observed in BCC contact regions, particularly in well-established $4 \mathrm{~T} 1$ clusters at later timepoints, pointing to the importance of inter-BCC communication for cluster formation and maintenance. Such intercellular communication was observed by us in an in vivo model of $\mathrm{BC}$ brain metastases [19], where Cx43 was shown to localise at both BCC-BCC and BCC-BMEC contact points. These observations point to a role of Cx43 for TEM across the BBB.

Integrins and adaptor molecules such as FAK, besides their adhesion and structural function, are also involved in signalling pathways, regulating several cellular mechanisms such as proliferation and migration [67]. FAK is a non-receptor tyrosine kinase and the most relevant signalling molecule in focal adhesion assembly and disassembly [68]. Moreover, it was described to have a pleiotropic action in tumour cell survival, proliferation, invasion, and metastasis formation through activation by integrin signalling [11,68], while in ECs it plays a key role in adhesion, angiogenesis and vascular permeability [69,70]. Interestingly, FAK has been associated with endothelial permeability regulation in pulmonary ECs, as endothelial FAK loss upon thrombin stimulus promoted a sustained decrease in transendothelial electric resistance [71]. Moreover, the activation of FAK and proto-oncogene tyrosine-protein kinase Src in ECs was shown to promote endothelial permeability through junctional impairment [70], particularly in response to tumour cell contact [15]. The herewith found overall decrease in FAK in prolonged BMEC exposure to BCCs, taken together with the junctional impairment observed in BMECs, suggests that FAK is associated with tumour transmigration by increasing endothelial permeability. 
In epithelial cells, $\alpha 6 \beta 4$-integrin signalling is known to relate to its dissociation from the basement membrane and translocation to the cytoplasm and nucleus, promoting the activation of pathways, such as phosphoinositide 3-kinase and extracellular signal-regulated kinase [72]. Similarly, in cancer and particularly in BC, upon $\alpha 6 \beta 4$-integrin phosphorylation (at $\beta 4$ subunit level in the cytoplasmatic tail), integrin release from the hemidesmosome occurs, perpetuating invasive signalling and promoting migration, invasion, proliferation, and tumourigenesis $[73,74]$. Curiously, in vascular ECs, the translocation of $\beta 4$-integrin into the nucleus has been associated with cell apoptosis [75]. The present study reports an alteration of $\beta 4$-integrin to nuclear sub-localisation in b.End5 cells in the proximity of $4 \mathrm{~T} 1$ cells, which is consistent with either the loss of cellular adhesion and migration activation [72] or with the activation of cell death processes [75] that could account for the endothelial holes observed at latter stages of BMEC-BCC contact. Additionally, we showed an increase in $\beta 4$-integrin in $4 \mathrm{~T} 1$ cells, until $6 \mathrm{~h}$ of contact with the endothelium, which suggests a potential involvement of this protein in the migration and invasive mechanisms. In fact, it has been demonstrated that cancer cells can extend invadopodia when transmigrating through vessels [20], where some of the involved proteins described include integrins and FAK $[76,77]$. Furthermore, the preference for invadopodia to initiate where both FAK and integrins associate has been reported, particularly the $\alpha 5 \beta 1$-integrin, leading to signalling activation during invadopodium initiation and maturation [76]. Studies have shown that integrins participate in invadosome formation and progression; however, only $\beta 1$ and $\beta 3$ have been described [76]. Here, we suggest that $\beta 4$-integrin is involved in invadopodia establishment and ultimately enhances the invasiveness phenotype of BCCs. Interestingly, we observed such a phenotype as early as at $3 \mathrm{~h}$ of BCC-BMEC contact. Such invadopodium extension is particularly evident through $\beta 4$-integrin staining, leaving the question of whether this protein could have a role in this process. Importantly, authors have already described the recruitment of FAK by $\beta 4$-integrin, and the consequent formation of the complex FAK/ $\beta 4$-integrin, with FAK activation, driving protein kinase $\mathrm{B}(\mathrm{Akt})$ signalling regulation in cancer $[13,78]$. We have also recently shown that FAK/ $\beta 4$-integrin colocalisation appears to be pivotal for in vivo BC brain metastasis establishment [19]. In accordance, here we found that, together with FAK, BCCs also express $\beta 4$-integrin, which co-expressed at advanced stages of the extravasation process, suggesting the activation of these signalling pathways during metastasis formation.

\section{Materials and Methods}

\subsection{Cell Culture Conditions}

Mouse BALB/c brain endothelioma cell line b.End5 (ECACC, Salisbury, UK) was used as a simplified BBB in vitro model. b.End5 cells were grown in Dulbecco's modified Eagle's medium (DMEM, Gibco, Life Technologies, New York, NY, USA) supplemented with $10 \%(v / v)$ foetal bovine serum (FBS, Biochrom AG, Berlin, DE), 1\% (v/v) non-essential amino acids (Biochrom AG, Berlin, DE), 2 mM L-glutamine (Biochrom AG, Berlin, DE), $1 \mathrm{mM}$ sodium pyruvate (Biochrom $\mathrm{AG}$ ) and $1 \%(v / v)$ antibiotic-antimycotic solution (Sigma Aldrich, St. Louis, MO, USA).

The murine mammary carcinoma triple-negative 4T1 cell line (ATCC, Middlesex, UK) was also used. 4T1 cells were cultured in RPMI 1640 (Sigma Aldrich, St. Louis, MO, USA) supplemented with $2 \mathrm{mM}$ L-glutamine and $5 \%(v / v)$ FBS. Both cell lines were maintained at $37^{\circ} \mathrm{C}$ in humid atmosphere enriched with $5 \% \mathrm{CO}_{2}$.

\subsection{SS Application}

Confluent monolayers of b.End5 cells were exposed to laminar non-pulsatile SS, achieved by orbital rotation, as previously described [17], using an orbital shaker (Grant Bio Orbital shaker PSU-10i, Grant Instruments, Cambridge Ltd., Royston, UK) positioned inside the incubator. The SS applied was estimated using the following equation:

$$
\tau_{w}=\alpha \sqrt{\rho \eta(2 \pi \mathrm{f})^{3}},
$$


where $\tau \mathrm{w}$ is the SS value $\left(\mathrm{dyn} / \mathrm{cm}^{2}\right), \alpha$ is the orbital radius of rotation of the shaker $(0.5 \mathrm{~cm}), \rho$ is the density of the cell culture medium $\left(1.01 \mathrm{~g} / \mathrm{cm}^{3}\right), \eta$ is the cell medium viscosity $\left(0.0075 \mathrm{dyn} / \mathrm{cm}^{2}\right.$ at $\left.37^{\circ} \mathrm{C}\right)$, and $\mathrm{f}$ corresponds to rotations per second (rps) $[79,80]$. Physiological magnitudes of SS such as $1.5 \mathrm{dyn} / \mathrm{cm}^{2}$ have been reported $[81,82]$ and were used in our assays, corresponding to a rotational frequency of $1.67 \mathrm{rps}(100 \mathrm{rpm})$. A progressive ramping was made with a $0.17 \mathrm{rps}(10 \mathrm{rpm})$ increase every $30 \mathrm{~min}$ until reaching physiological SS. SS conditions were maintained for $48 \mathrm{~h}$.

\subsection{BC Brain Metastasis Formation In Vitro Model Establishment}

As an in vitro model that mimics the $\mathrm{BC}$ brain metastasis development, mixed cultures of b.End5 and $4 \mathrm{~T} 1$ cells were implemented. b.End5 cells $\left(5 \times 10^{4}\right.$ cells $\left./ \mathrm{mL}\right)$ were plated onto glass coverslips covered with rat tail collagen I (Corning, New York, NY, USA) at $50 \mu \mathrm{g} / \mathrm{mL}$. After $48 \mathrm{~h}$, physiological SS was applied for $24 \mathrm{~h}$. In order to distinguish both cell populations, $4 \mathrm{~T} 1$ cells were labelled with CellTracker ${ }^{\mathrm{TM}}$ Red CMTPX Dye $(2.5 \mu \mathrm{M}$; Thermo Fisher Scientific, Waltham, MA, USA), in DMEM, and then plated $\left(1 \times 10^{5}\right.$ cells $\left./ \mathrm{mL}\right)$ on top of b.End5 monolayers. Mixed cultures were kept on SS conditions for 1, 3, 6 and $24 \mathrm{~h}$, timepoints after which cells were fixed with $4 \%(w / v)$ paraformaldehyde (PFA, Sigma-Aldrich, St. Louis, MO, USA) in phosphate-buffered saline (PBS) for $20 \mathrm{~min}$ at room temperature. Assays were run in parallel for each cell type alone, as controls. The experimental design is depicted in Figure 9.

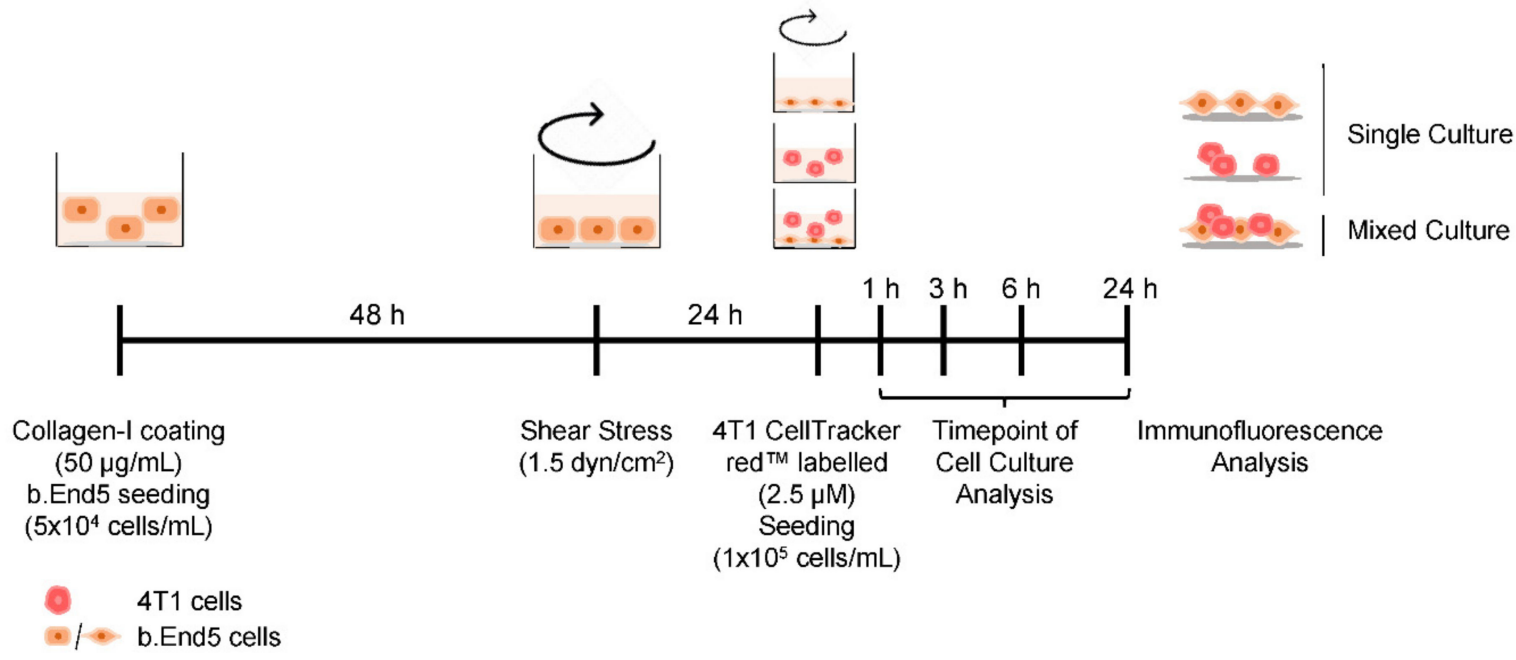

Figure 9. Schematic representation of the experimental design of the mouse breast cancer brain METABLE 5. was seeded at the concentration of $5 \times 10^{4}$ cells $/ \mathrm{mL}$ onto collagen-I coated coverslips $(50 \mu \mathrm{g} / \mathrm{mL})$ to allow a confluent monolayer formation during $48 \mathrm{~h}$, after which physiological laminar shear stress $\left(1.5 \mathrm{dyn} / \mathrm{cm}^{2}\right)$ was applied by orbital rotation. After $24 \mathrm{~h}$, mixed culture was initiated by the seeding of $1 \times 10^{5}$ cell/mL murine mammary carcinoma triple-negative cells (4T1) previously labelled with CellTracker ${ }^{\mathrm{TM}}$ DMTPX Red Dye $(2.5 \mu \mathrm{M})$ onto b.End5 monolayers. Single cultures (b.End5 and $4 \mathrm{~T} 1$ cells) were run in parallel, as controls. Cell cultures were fixed at 1, 3, 6 and $24 \mathrm{~h}$ for immunofluorescence analysis.

\subsection{Immunofluorescence}

Phenotypic alterations in endothelial and tumour cells in single and mixed cultures along time were evaluated by immunofluorescence analysis of junctional proteins ( $\mathrm{ZO}-1$, $\beta$-catenin, Cx43), transcellular transport-associated protein (cav-1), cytoskeleton-associated proteins (MLCK and p-MLC) and adhesion-associated proteins (FAK and $\beta 4$-integrin). Following fixation, cells were permeabilised for $5 \mathrm{~min}$, blocked for $60 \mathrm{~min}$ at room temperature, and incubated overnight at $4{ }^{\circ} \mathrm{C}$ with the primary antibodies and thereafter with the corresponding secondary antibodies for $60 \mathrm{~min}$ at room temperature, in the dark, as specified in Table 1 . Both primary and secondary antibodies were diluted in corresponding blocking solutions. Nuclei were counterstained with Hoechst 33342 dye (Thermo Fisher Sci- 
entific; 1:1000 in PBS) for $10 \mathrm{~min}$ at room temperature. Cells were washed three times with PBS between incubations. Methanol dehydrated cells were then mounted in microscopy slides with DPX (Merck Millipore, Burlington, MA, EUA), properly dried and stored at $4{ }^{\circ} \mathrm{C}$ until image acquisition.

Table 1. Summary of the experimental conditions for immunofluorescence analysis.

\begin{tabular}{|c|c|c|c|c|}
\hline Target Protein & Permeabilisation & Blocking & Primary Antibody & Secondary Antibody \\
\hline$\beta$-catenin & $\begin{array}{c}0.3 \% \\
\text { Triton } \mathrm{X}-100\end{array}$ & $3 \%$ BSA & $\begin{array}{l}\beta \text {-catenin }(1: 100) \\
\text { Thermo Fisher Scientific, } \\
\text { \#71-2700, Rabbit }\end{array}$ & $\begin{array}{c}\text { Alexa Fluor }^{\circledR} 488(1: 500) \\
\text { Thermo Fisher Scientific, \#A21206, } \\
\text { Goat Anti-Rabbit }\end{array}$ \\
\hline$\beta 4$-Integrin & $\begin{array}{c}0.3 \% \\
\text { Triton } X-100\end{array}$ & $3 \%$ BSA & $\begin{array}{c}\text { ß4-integrin (1:50) } \\
\text { Santa Cruz Biotechnology, } \\
\text { \#sc-514426, Mouse }\end{array}$ & $\begin{array}{c}\text { Alexa Fluor }^{\circledR} 488(1: 500) \\
\text { Thermo Fisher Scientific, \#A11001 } \\
\text { Goat Anti-Mouse }\end{array}$ \\
\hline Cav-1 & $\begin{array}{c}0.1 \% \text { Saponin in } 3 \% \\
\text { BSA }\end{array}$ & $\begin{array}{c}0.1 \% \text { Saponin in } 3 \% \\
\text { BSA }\end{array}$ & $\begin{array}{l}\text { Caveolin-1 (1:100) } \\
\text { Cell Signaling, } \\
\text { \#3238S, Rabbit }\end{array}$ & $\begin{array}{c}\text { Alexa Fluor }^{\circledR} 488(1: 500) \\
\text { Thermo Fisher Scientific, \#A21206, } \\
\text { Goat Anti-Rabbit }\end{array}$ \\
\hline $\mathrm{Cx} 43$ & $\begin{array}{l}0.3 \% \\
\text { Triton } \mathrm{X}-100\end{array}$ & $3 \%$ BSA & $\begin{array}{l}\text { Cx43 (1:50) } \\
\text { Thermo Fisher Scientific, } \\
\text { \#35-5000, Mouse }\end{array}$ & $\begin{array}{c}\text { Alexa Fluor }^{\circledR} 488(1: 500) \\
\text { Thermo Fisher Scientific, \#A11001 } \\
\text { Goat Anti-Mouse }\end{array}$ \\
\hline FAK & $\begin{array}{l}0.3 \% \\
\text { Triton } X-100\end{array}$ & $3 \% \mathrm{BSA}$ & $\begin{array}{c}\text { FAK }(1: 200) \\
\text { Abcam, } \\
\text { \#ab131435, Rabbit }\end{array}$ & $\begin{array}{l}\text { Alexa Fluor }^{\circledR} 488(1: 500) \\
\text { Thermo Fisher Scientific, \#A21206, } \\
\text { Goat Anti-Rabbit }\end{array}$ \\
\hline MLCK & $\begin{array}{c}0.3 \% \\
\text { Triton } X-100\end{array}$ & $3 \%$ BSA & $\begin{array}{l}\text { MLCK }(1: 100) \\
\text { Thermo Fisher Scientific, } \\
\text { \#PA515177, Rabbit }\end{array}$ & $\begin{array}{c}\text { Alexa Fluor }^{\circledR} 488(1: 500) \\
\text { Thermo Fisher Scientific, \#A21206, } \\
\text { Goat Anti-Rabbit }\end{array}$ \\
\hline p-MLC & $\begin{array}{c}0.3 \% \\
\text { Triton X-100 }\end{array}$ & $3 \%$ BSA & $\begin{array}{l}\text { p-MLC }(1: 400) \\
\text { Thermo Fisher Scientific, } \\
\text { \#MA5-15163, Mouse }\end{array}$ & $\begin{array}{c}\text { Alexa Fluor }^{\circledR} 488(1: 500) \\
\text { Thermo Fisher Scientific, \#A11001 } \\
\text { Goat Anti-Mouse }\end{array}$ \\
\hline ZO-1 & $\begin{array}{c}0.3 \% \\
\text { Triton X-100 }\end{array}$ & $3 \%$ BSA & $\begin{array}{l}\text { ZO-1 (1:200) } \\
\text { Thermo Fisher Scientific, } \\
\text { \#40-2200, Rabbit }\end{array}$ & $\begin{array}{c}\text { Alexa Fluor }^{\circledR} 488(1: 500) \\
\text { Thermo Fisher Scientific, \#A21206, } \\
\text { Goat Anti-Rabbit }\end{array}$ \\
\hline
\end{tabular}

BSA, bovine serum albumin; cav-1, caveolin-1; cx43, connexin 43; FAK, focal adhesion kinase; MLCK, myosin light chain kinase; p-MLC, phosphorylated myosin light chain; ZO-1, zonula occludens-1.

\subsection{Image Acquisition and Data Analysis}

Immunolabellings were examined using an Olympus BX60 microscope equipped with Olympus U-RFL-T Mercury lamp and Hamamatsu Orca R2 cooled monochromatic CCD camera, using 40x and 100x oil objectives.

For all stainings, 10 fields per condition were analysed. Data analysis was performed using Image 1.29x software (National Institutes of Health, Bethesda, MD, USA), namely for the definition of quantification area, evaluation of mean intensity and their representation by plot profile, cell cluster number and area, as well the number of invadopodia forming cells. Icy (Institute Pasteur and France BioImaging, Paris, France) software was employed for the quantification of membrane and nuclear mean intensity, cytoplasmatic and total cell intensity, evaluation of cell morphology parameters such as cell elongation, and quantification of gaps in membrane staining (detailed in Table S1).

\subsection{Statistical Analysis}

Results were analysed using GraphPad Prism ${ }^{\circledR} 6.0$ (GraphPad Software, San Diego, CA, USA) and are expressed as mean \pm SEM. The results represent the average of three independent experiments $(n=3)$. Two-tailed Student's $t$-test and one-way ANOVA (parametric test for data with normal distribution) or a Mann-Whitney test or a Kruskal-Wallis test (non-parametric tests for data with an abnormal distribution, $\alpha=0.05$ ) was performed 
for comparisons between conditions and timepoints (Table S1). Statistically significant differences were considered when $p<0.05$.

\section{Conclusions}

In this work, we implemented a new in vitro model to study BCC ' interaction with the BBB endothelium, encompassing the effect of physiological SS, which represents an invaluable tool for studies of malignant cells' extravasation across brain microvasculature and brain metastases formation. The results obtained allowed a comprehensive understanding of the players and signalling molecules involved in BCC-BMEC interaction, differentiating the molecular alterations occurring in malignant cells from those in BBB ECs. Importantly, it provided novel insights into conflicting or so far undetermined aspects of the extravasation process. We can conclude that exposure to BCCs leads to increased paracellular and transcellular permeability of the BBB ECs, culminating in severe disruption of the monolayer integrity, events associated with cytoskeleton alterations. On the other hand, invadopodia formation in BCCs via FAK and $\beta 4$-integrin highlights its pro-metastatic role, where adhesion molecules appear as key determinants of the extravasation process. Overall, the findings reported here disclose possible targets for modulation in order to devise strategies to prevent the extravasation of BCCs into the brain and, thus, to avoid the formation of uncurable metastases.

Supplementary Materials: The following are available online at https://www.mdpi.com/article/10 .3390/ijms22137057/s1, Table S1: Data analysis of all studied parameters.

Author Contributions: Conceptualization, M.A.B.; Data Curation, J.G.-P., A.R.G. and I.F.; Formal analysis, J.G.-P.; Funding acquisition, M.A.B.; Investigation, J.G.-P., A.R.G. and I.F.; Methodology, J.G.-P., A.R.G. and I.F.; Project administration, M.A.B.; Resources, M.A.B. and R.M.; Supervision, M.A.B.; Validation, M.A.B.; Writing—original draft preparation, J.G.-P.; Writing—review and editing, J.G.-P., A.R.G., I.F., R.M. and M.A.B. All authors have read and agreed to the published version of the manuscript.

Funding: This work was funded by the Portuguese Foundation for Science and Technology (FCT), Portugal, grant numbers PTDC/MED-ONC/29402/2017, UIDP/04138/2020 and UIDB/04138/2020. We also acknowledge FCT financial support of J.G.-P. (SFRH/BD/145522/2019) and of A.R.G. (2020.07115.BD).

Institutional Review Board Statement: Not applicable.

Informed Consent Statement: Not applicable.

Data Availability Statement: Not applicable.

Acknowledgments: We acknowledge the Faculty of Sciences of the University of Lisbon's Microscopy Facility, a node of the Portuguese Platform of BioImaging (PPBI-POCI-01-0145-FEDER-022122). We also acknowledge Luís Marques (Faculty of Sciences, University of Lisbon) for the excellent technical support with image acquisition.

Conflicts of Interest: The authors declare no conflict of interest.

$\begin{array}{ll}\text { Abbreviations } \\ \text { AJ } & \text { Adherens Junction } \\ \text { BBB } & \text { Blood-Brain Barrier } \\ \text { BC } & \text { Breast Cancer } \\ \text { BCCs } & \text { Breast Cancer Cells } \\ \text { BMECs } & \text { Brain Microvascular Endothelial Cells } \\ \text { BSA } & \text { Bovine Serum Albumin } \\ \text { Cav-1 } & \text { Caveolin-1 } \\ \text { Cx43 } & \text { Connexin } 43\end{array}$




$\begin{array}{ll}\text { ECs } & \text { Endothelial Cells } \\ \text { FAK } & \text { Focal Adhesion Kinase } \\ \text { FBS } & \text { Foetal Bovine Serum } \\ \text { GJ } & \text { Gap Junction } \\ \text { MLC } & \text { Myosin Light Chain } \\ \text { MLCK } & \text { Myosin Light Chain Kinase } \\ \text { PBS } & \text { Phosphate Buffer Solution } \\ \text { p-MLC } & \text { Phosphorylated Myosin Light Chain } \\ \text { SS } & \text { Shear Stress } \\ \text { TJ } & \text { Tight Junction } \\ \text { TEM } & \text { Transendothelial Migration } \\ \text { ZO-1 } & \text { Zonula Occludens-1 }\end{array}$

\section{References}

1. Sung, H.; Ferlay, F.; Siegel, R.L.; Laversanne, M.; Soerjomataram, I.; Jemal, A.; Bray, F. Global cancer statistics 2020: GLOBOCAN estimates of incidence and mortality worldwide for 36 cancers in 185 countries. CA Cancer J. Clin. 2021, 71, 209-249. [CrossRef]

2. Kimberly, D.; Miller, K.D.; Nogueira, L.; Mariotto, A.B.; Rowland, J.H.; Yabroff, K.R.; Alfano, C.M.; Jemal, A.; Kramer, J.L.; Siegel, R.L. Cancer treatment and survivorship statistics, 2019. CA Cancer J. Clin. 2019, 69, 363-385.

3. Riggio, A.I.; Varley, K.E.; Welm, A.L. The lingering mysteries of metastatic recurrence in breast cancer. Br. J. Cancer 2021, 124, 13-26. [CrossRef] [PubMed]

4. Branco, V.; Pimentel, J.; Brito, M.A.; Carvalho, C. Thioredoxin, glutathione and related molecules in tumors of the nervous system. Curr. Med. Chem. 2020, 27, 1878-1900. [CrossRef]

5. Krishnan, M.; Krishnamurthy, J.; Shonka, N. Targeting the sanctuary site: Options when breast cancer metastasizes to the brain. Oncology 2019, 33, 683730.

6. Martin, A.M.; Cagney, D.N.; Catalano, P.J.; Warren, L.E.; Bellon, J.R.; Punglia, R.S.; Claus, E.B.; Lee, E.Q.; Wen, P.Y.; Haas-Kogan, D.A.; et al. Brain metastases in newly diagnosed breast cancer: A population-based study. JAMA Oncol. 2017, 3, $1069-1077$. [CrossRef] [PubMed]

7. Custodio-Santos, T.; Videira, M.; Brito, M.A. Brain metastasization of breast cancer. Biochim. Biophys. Acta Rev. Cancer 2017, 1868, 132-147. [CrossRef]

8. Sökeland, G.; Schumacher, U. The functional role of integrins during intra- and extravasation within the metastatic cascade. Mol. Cancer 2019, 18, 12. [CrossRef] [PubMed]

9. Kang, S.A.; Blache, C.A.; Bajana, S.; Hasan, N.; Kamal, M.; Morita, Y.; Gupta, V.; Tsolmon, B.; Suh, K.S.; Gorenstein, D.G.; et al The effect of soluble E-selectin on tumor progression and metastasis. BMC Cancer 2016, 16, 331.

10. Blecharz, K.G.; Colla, R.; Rohde, V.; Vajkoczy, P. Control of the blood-brain barrier function in cancer cell metastasis. Biol. Cell 2015, 107, 342-371. [CrossRef]

11. Schaller, M.D. Cellular functions of FAK kinases: Insight into molecular mechanisms and novel functions. J. Cell Sci. 2010, 123, 1007-1013. [CrossRef] [PubMed]

12. Kouam, P.N.; Bühler, H.; Hero, T.; Irenäus, A.; Adamietz, I.A. The increased adhesion of tumor cells to endothelial cells after irradiation can be reduced by FAK-inhibition. Radiat. Oncol. 2019, 14, 25. [CrossRef] [PubMed]

13. Tai, Y.L.; Chu, P.Y.; Lai, I.R.; Wang, M.Y.; Tseng, H.Y.; Guan, J.L.; Liou, J.Y.; Shen, T.L. An EGFR/Src-dependent $\beta 4$ integrin/FAK complex contributes to malignancy of breast cancer. Sci. Rep. 2015, 5, 16408. [CrossRef] [PubMed]

14. Chen, X.L.; Nam, J.-O.; Jean, C.; Lawson, C.; Walsh, C.T.; Goka, E.; Lim, S.-T.; Tomar, A.; Tancioni, I.; Uryu, S.; et al. VEGF-induced vascular permeability is mediated by FAK. Dev. Cell 2012, 22, 146-157. [CrossRef] [PubMed]

15. Jean, C.; Chen, X.L.; Nam, J.-O.; Tancioni, I.; Uryu, S.; Lawson, C.; Ward, K.K.; Walsh, C.T.; Miller, N.L.G.; Ghassemian, M.; et al. Inhibition of endothelial FAK activity prevents tumor metastasis by enhancing barrier function. J. Cell Biol. 2014, 204, 247-263. [CrossRef]

16. Cardoso, F.L.; Brites, D.; Brito, M.A. Looking at the blood-brain barrier: Molecular anatomy and possible investigation approaches. Brain Res. Rev. 2010, 64, 328-363. [CrossRef]

17. Garcia, A.R.; Godinho-Pereira, J.; Figueira, I.; Malhó, R.; Brito, M.A. Replicating the blood-brain barrier properties in an in vitro model: Effects of hydrocortisone and/or shear stress. Arch. Anat. 2019, 8, 4-20.

18. Cucullo, L.; Hossain, M.; Puvenna, V.; Marchi, N.; Janigro, D. The role of shear stress in Blood-Brain Barrier endothelial physiology. BMC Neurosci. 2011, 12, 40. [CrossRef]

19. Figueira, I.; Galego, S.; Custódio-Santos, T.; Vicente, R.; Molnár, K.; Haskó, J.; Malhó, R.; Videira, M.; Wilhelm, I.; Krizbai, I.; et al. Picturing breast cancer brain metastasis development to unravel molecular players and cellular crosstalk. Cancers 2021, 13, 910. [CrossRef] [PubMed]

20. Leong, H.S.; Robertson, A.E.; Stoletov, K.; Leith, S.J.; Chin, C.A.; Chien, A.E.; Hague, M.N.; Ablack, A.; Carmine-Simmen, K.; McPherson, V.A.; et al. Invadopodia are required for cancer cell extravasation and are a therapeutic target for metastasis. Cell Rep. 2014, 8, 1558-1570. [CrossRef] [PubMed] 
21. Schumacher, D.; Strilic, B.; Sivaraj, K.K.; Wettschureck, N.; Offermanns, S. Platelet-derived nucleotides promote tumor-cell transendothelial migration and metastasis via $\mathrm{P}_{2} \mathrm{Y}_{2}$ receptor. Cancer Cell 2013, 24, 130-137. [CrossRef] [PubMed]

22. Strilic, B.; Offermanns, S. Intravascular survival and extravasation of tumor cells. Cancer Cell 2017, 32, 282-293. [CrossRef]

23. Herman, H.; Fazakas, C.; Hasko, J.; Molnar, K.; Meszaros, A.; Nyul-Toth, A.; Szabo, G.; Erdelyi, F.; Ardelean, A.; Hermenean, A.; et al. Paracellular and transcellular migration of metastatic cells through the cerebral endothelium. J. Cell. Mol. Med. 2019, 23, 2619-2631. [CrossRef] [PubMed]

24. Haskó, J.; Fazakas, C.; Molnár, K.; Mészáros, Á.; Patai, R.; Szabó, G.; Erdélyi, F.; Nyúl-Tóth, A.; Győri, F.; Kozma, M.; et al. Response of the neurovascular unit to brain metastatic breast cancer cells. Acta Neuropathol. Commun. 2019, 7, 133. [CrossRef] [PubMed]

25. Reymond, N.; d'Agua, B.B.; Ridley, A.J. Crossing the endothelial barrier during metastasis. Nat. Rev. Cancer 2013, 13, 858-870. [CrossRef]

26. Shen, Q.; Wu, M.H.; Yuan, S.Y. Endothelial contractile cytoskeleton and microvascular permeability. Cell Health Cytoskelet. 2009, 2009, 43-50.

27. Zhou, X.; Liu, Y.; You, J.; Zhang, H.; Zhang, X.; Ye, L. Myosin light-chain kinase contributes to the proliferation and migration of breast cancer cells through cross-talk with activated ERK1/2. Cancer Lett. 2008, 270, 312-327. [CrossRef] [PubMed]

28. Khuon, S.; Liang, L.; Dettman, R.W.; Sporn, P.H.; Wysolmerski, R.B.; Chew, T.L. Myosin light chain kinase mediates transcellular intravasation of breast cancer cells through the underlying endothelial cells: A three-dimensional FRET study. J. Cell Sci. 2010, 123, 431-440. [CrossRef]

29. Andreone, B.J.; Chow, B.W.; Tata, A.; Lacoste, B.; Ben-Zvi, A.; Bullock, K.; Deik, A.A.; Ginty, D.D.; Clish, C.B.; Gu, C. Blood-brain barrier permeability is regulated by lipid transport-dependent suppression of caveolae-mediated transcytosis. Neuron 2017, 94 , 581-594.e5. [CrossRef]

30. Qian, X.L.; Pan, Y.H.; Huang, Q.Y.; Shi, Y.B.; Huang, Q.Y.; Hu, Z.Z.; Xiong, L.X. Caveolin-1: A multifaceted driver of breast cancer progression and its application in clinical treatment. OncoTargets Ther. 2019, 12, 1539-1552. [CrossRef]

31. Li, S.; Chen, Y.; Zhang, Y.; Jiang, X.; Jiang, Y.; Qin, X.; Yang, H.; Wu, C.; Liu, Y. Shear stress promotes anoikis resistance of cancer cells via caveolin-1-dependent extrinsic and intrinsic apoptotic pathways. J. Cell. Physiol. 2019, 234, 3730-3743. [CrossRef] [PubMed]

32. Wang, K.; Zhu, X.; Chen, Y.; Yin, Y.; Ma, T. Tubeimoside V sensitizes human triple negative breast cancer MDA-MB-231 cells to anoikis via regulating caveolin-1-related signaling pathways. Arch. Biochem. Biophys. 2018, 646, 10-15. [CrossRef] [PubMed]

33. Chiu, W.-T.; Lee, H.-T.; Huang, F.-J.; Aldape, K.D.; Yao, J.; Steeg, P.S.; Chou, C.-Y.; Lu, Z.; Xie, K.; Huang, S. Caveolin-1 upregulation mediates suppression of primary breast tumor growth and brain metastases by stat3 inhibition. Cancer Res. 2011, 71, 4932-4943. [CrossRef]

34. Wu, J.I.; Wang, L.H. Emerging roles of gap junction proteins connexins in cancer metastasis, chemoresistance and clinical application. J. Biomed. Sci. 2019, 26, 8. [CrossRef]

35. Johnson, A.M.; Roach, J.P.; Hu, A.; Stamatovic, S.M.; Michal, R.; Zochowski, M.R.; Keep, R.F.; Andjelkovic, A.V. Connexin 43 gap junctions contribute to brain endothelial barrier hyperpermeability in familial cerebral cavernous malformations type III by modulating tight junction structure. FASEB J. 2018, 32, 2615-2629. [CrossRef] [PubMed]

36. Phillips, S.L.; Williams, C.B.; Zambrano, J.N.; Williams, C.J.; Yeh, E.S. Connexin 43 in the development and progression of breast cancer: What's the connection? Int. J. Oncol. 2017, 51, 1005-1013. [CrossRef]

37. Naser Al Deen, N.; AbouHaidar, M.; Talhouk, R. Connexin43 as a tumor suppressor: Proposed Connexin43 mRNA-circularRNAsmicroRNAs axis towards prevention and early detection in breast cancer. Front. Med. 2019, 6, 192. [CrossRef]

38. Pollmann, M.-A.; Shao, Q.; Laird, D.W.; Sandig, M. Connexin 43 mediated gap junctional communication enhances breast tumor cell diapedesis in culture. Breast Cancer Res. 2005, 7, R522-R534. [CrossRef]

39. Zihni, C.; Mills, C.; Matter, K.; Balda, M.S. Tight junctions: From simple barriers to multifunctional molecular gates. Nat. Rev. Mol. Cell Biol. 2016, 17, 564-580. [CrossRef]

40. Rigor, R.R.; Shen, Q.; Pivetti, C.D.; Wu, M.H.; Yuan, S.Y. Myosin light chain kinase signaling in endothelial barrier dysfunction. Med. Res. Rev. 2013, 33, 911-933. [CrossRef]

41. Roy-Luzarraga, M.; Hodivala-Dilke, K. Molecular pathways: Endothelial cell FAK-A target for cancer treatment. Clin. Cancer Res. 2016, 22, 3718. [CrossRef] [PubMed]

42. Vieira, A.F.; Ribeiro, A.S.; Dionisio, M.R.; Sousa, B.; Nobre, A.R.; Albergaria, A.; Santiago-Gomez, A.; Mendes, N.; Gerhard, R.; Schmitt, F.; et al. P-cadherin signals through the laminin receptor alpha6beta4 integrin to induce stem cell and invasive properties in basal-like breast cancer cells. Oncotarget 2014, 5, 679-692. [CrossRef]

43. Chiang, S.P.; Cabrera, R.M.; Segall, J.E. Tumor cell intravasation. Am. J. Physiol. Cell Physiol. 2016, 311, C1-C14. [CrossRef]

44. Wang, W.-C.; Zhang, X.-F.; Peng, J.; Li, X.-F.; Wang, A.-L.; Bie, Y.-Q.; Shi, L.-H.; Lin, M.-B.; Zhang, X.-F. Survival Mechanisms and influence factors of circulating tumor cells. Biomed. Res. Int. 2018, 2018, 6304701. [CrossRef] [PubMed]

45. Aceto, N.; Bardia, A.; Miyamoto, D.T.; Donaldson, M.C.; Wittner, B.S.; Spencer, J.A.; Yu, M.; Pely, A.; Engstrom, A.; Zhu, H.; et al. Circulating tumor cell clusters are oligoclonal precursors of breast cancer metastasis. Cell 2014, 158, 1110-1122. [CrossRef] [PubMed]

46. Lintz, M.; Muñoz, A.; Reinhart-King, C.A. The mechanics of single cell and collective migration of tumor cells. J. Biomech. Eng. 2017, 139, 0210051-0210059. [CrossRef] [PubMed] 
47. Yang, Y.; Zheng, H.; Zhan, Y.; Fan, S. An emerging tumor invasion mechanism about the collective cell migration. Am. J. Transl. Res. 2019, 11, 5301-5312. [PubMed]

48. Plutoni, C.; Keil, S.; Zeledon, S.; Delsin, L.E.A.; Decelle, B.; Roux, P.P.; Carréno, S.; Emery, G. Misshapen coordinates protrusion restriction and actomyosin contractility during collective cell migration. Nat. Commun. 2019, 10, 3940. [CrossRef] [PubMed]

49. Khalil, A.A.; Ilina, O.; Vasaturo, A.; Venhuizen, J.-H.; Vullings, M.; Venhuizen, V.; Bilos, A.; Figdor, C.; Span, P.N.; Friedl, P. Leader cell activity and collective invasion by an autocrine nucleotide loop through connexin- 43 hemichannels and ADORA1. bioRxiv 2019. Available online: https://www.biorxiv.org/content/10.1101/2019.12.30.888958v1.full (accessed on 12 January 2021).

50. Chen, M.B.; Whisler, J.A.; Jeon, J.S.; Kamm, R.D. Mechanisms of tumor cell extravasation in an in vitro microvascular network platform. Integr. Biol. 2013, 5, 1262-1271. [CrossRef]

51. Wrenn, E.D.; Yamamoto, A.; Moore, B.M.; Huang, Y.; McBirney, M.; Thomas, A.J.; Greenwood, E.; Rabena, Y.F.; Rahbar, H.; Partridge, S.C.; et al. Regulation of collective metastasis by nanolumenal signaling. Cell 2020, 183, 395-410.e19. [CrossRef] [PubMed]

52. Avraham, H.K.; Jiang, S.; Fu, Y.; Nakshatri, H.; Ovadia, H.; Avraham, S. Angiopoietin-2 mediates blood-brain barrier impairment and colonization of triple-negative breast cancer cells in brain. J. Pathol. 2014, 232, 369-381. [CrossRef]

53. Li, B.; Zhao, W.D.; Tan, Z.M.; Fang, W.G.; Zhu, L.; Chen, Y.H. Involvement of Rho/ROCK signalling in small cell lung cancer migration through human brain microvascular endothelial cells. FEBS Lett. 2006, 580, 4252-4260. [CrossRef]

54. Fan, J.; Fu, B.M. Quantification of malignant breast cancer cell MDA-MB-231 transmigration across brain and lung microvascular endothelium. Ann. Biomed. Eng. 2016, 44, 2189-2201. [CrossRef] [PubMed]

55. Weidert, E.; Pohler, S.E.; Gomez, E.W.; Dong, C. Actinomyosin contraction, phosphorylation of VE-cadherin, and actin remodeling enable melanomainduced endothelial cell-cell junction disassembly. PLoS ONE 2014, 9, e108092.

56. Carman, C.V. Mechanisms for transcellular diapedesis: Probing and pathfinding by 'invadosome-like protrusions'. J. Cell Sci. 2009, 122, 3025-3035. [CrossRef] [PubMed]

57. Deng, J.; Huang, Q.; Wang, F.; Liu, Y.; Wang, Z.; Wang, Z.; Zhang, Q.; Lei, B.; Cheng, Y. The role of caveolin-1 in blood-brain barrier disruption induced by focused ultrasound combined with microbubbles. J. Mol. Neurosci. 2012, 46, 677-687. [CrossRef]

58. Sotgia, F.; Williams, T.M.; Schubert, W.; Medina, F.; Minetti, C.; Pestell, R.G.; Lisanti, M.P. Caveolin-1 deficiency (-/ -) conveys premalignant alterations in mammary epithelia, with abnormal lumen formation, growth factor independence, and cell invasiveness. Am. J. Pathol. 2006, 168, 292-309. [CrossRef] [PubMed]

59. Cohen, A.W.; Hnasko, R.; Schubert, W.; Lisanti, M.P. Role of caveolae and caveolins in health and disease. Physiol. Rev. 2004, 84, 1341-1379. [CrossRef]

60. Nag, S.; Venugopalan, R.; Stewart, D.J. Increased caveolin-1 expression precedes decreased expression of occludin and claudin-5 during blood-brain barrier breakdown. Acta Neuropathol. 2007, 114, 459-469. [CrossRef]

61. Arvanitis, C.; Khuon, S.; Spann, R.; Ridge, K.M.; Chew, T.L. Structure and biomechanics of the endothelial transcellular circumferential invasion array in tumor invasion. PLoS ONE 2014, 9, e89758. [CrossRef]

62. Li, Q.; Sarna, S.K. Nuclear myosin II regulates the assembly of preinitiation complec for ICAM-1 gene transcription. Gastroenterology 2009, 137, 1051-1060.e3. [CrossRef]

63. Thomas, D.; Thiagarajan, P.S.; Rai, V.; Reizes, O.; Lathia, J.; Egelhoff, T. Increased cancer stem cell invasion is mediated by myosin IIB and nuclear translocation. Oncotarget 2016, 7, 47586-47592. [CrossRef] [PubMed]

64. Stoletov, K.; Strnadel, J.; Zardouzian, E.; Momiyama, M.; Park, F.D.; Kelber, J.A.; Pizzo, D.P.; Hoffman, R.; VandenBerg, S.R.; Klemke, R.L. Role of connexins in metastatic breast cancer and melanoma brain colonization. J. Cell Sci. 2013, 126, 904-913. [CrossRef] [PubMed]

65. Elzarrad, M.K.; Haroon, A.; Willecke, K.; Dobrowolski, R.; Gillespie, M.N.; Al-Mehdi, A.B. Connexin-43 upregulation in micrometastases and tumor vasculature and its role in tumor cell attachment to pulmonary endothelium. BMC Med. 2008, 6, 20. [CrossRef] [PubMed]

66. Tsai, C.F.; Cheng, Y.K.; Lu, D.Y.; Wang, S.L.; Chang, C.N.; Chang, P.C.; Yeh, W.L. Inhibition of estrogen receptor reduces connexin 43 expression in breast cancers. Toxicol. Appl. Pharmacol. 2018, 338, 182-190. [CrossRef]

67. Miranti, C.K.; Brugge, J.S. Sensing the environment: A historical perspective on integrin signal transduction. Nat. Cell Biol. 2002, 4, E83-E90. [CrossRef]

68. Zhao, J.; Guan, J.L. Signal transduction by focal adhesion kinase in cancer. Cancer Metastasis Rev. 2009, 28, 35-49. [CrossRef] [PubMed]

69. Infusino, G.A.; Jacobson, J.R. Endothelial FAK as a therapeutic target in disease. Microvasc. Res. 2012, 83, 89-96. [CrossRef]

70. Guo, X.; Eitnier, R.A.; Beard, R.S., Jr.; Meegan, J.E.; Yang, X.; Aponte, A.M.; Wang, F.; Nelson, P.R.; Wu, M.H. Focal adhesion kinase and Src mediate microvascular hyperpermeability caused by fibrinogen- $\gamma$ C-terminal fragments. PLoS ONE 2020, 15, e0231739. [CrossRef]

71. Mehta, D.; Tiruppathi, C.; Sandoval, R.; Minshall, R.D.; Holinstat, M.; Malik, A.B. Modulatory role of focal adhesion kinase in regulating human pulmonary arterial endothelial barrier function. J. Physiol. 2002, 539, 779-789. [CrossRef]

72. Nikolopoulos, S.N.; Blaikie, P.; Yoshioka, T.; Guo, W.; Puri, C.; Tacchetti, C.; Giancotti, F.G. Targeted deletion of the integrin $\beta 4$ signaling domain suppresses laminin-5-dependent nuclear entry of mitogen-activated protein kinases and NF-KB, causing defects in epidermal growth and migration. Mol. Cell. Biol. 2005, 25, 6090-6102. [CrossRef] [PubMed] 
73. Desgrosellier, J.S.; Cheresh, D.A. Integrins in cancer: Biological implications and therapeutic opportunities. Nat. Rev. Cancer 2010, 10, 9-22. [CrossRef]

74. Stewart, R.L.; O'Connor, K.L. Clinical significance of the integrin alpha6beta4 in human malignancies. Lab. Investig. 2015, 95, 976-986. [CrossRef]

75. Ge, D.; Kong, X.; Liu, W.; Zhao, J.; Su, L.; Zhang, S.; Zhang, Y.; Zhao, B.; Miao, J. Phosphorylation and nuclear translocation of integrin $\beta 4$ induced by a chemical small molecule contribute to apoptosis in vascular endothelial cells. Apoptosis 2013, 18, 1120-1131. [CrossRef] [PubMed]

76. Peláez, R.; Pariente, A.; Pérez-Sala, A.; Larrayoz, I.M. Integrins: Moonlighting proteins in invadosome formation. Cancers 2019, 11, 615. [CrossRef] [PubMed]

77. Genna, A.; Lapetina, S.; Lukic, N.; Twafra, S.; Meirson, T.; Sharma, V.P.; Condeelis, J.S.; Hava Gil-Henn, H. Pyk2 and FAK differentially regulate invadopodia formation and function in breast cancer cells. J. Cell Biol. 2018, 217, 375-395. [CrossRef]

78. Tai, Y.L.; Lai, I.R.; Peng, Y.J.; Ding, S.T.; Shen, T.L. Activation of focal adhesion kinase through an interaction with $\beta 4$ integrin contributes to tumorigenicity of colon cancer. FEBS Lett. 2016, 590, 1826-1837. [CrossRef]

79. Colgan, O.C.; Ferguson, G.; Collins, N.T.; Murphy, R.P.; Meade, G.; Cahill, P.A.; Cummins, P.M. Regulation of bovine brain microvascular endothelial tight junction assembly and barrier function by laminar shear stress. Am. J. Physiol. Heart Circ. Physiol. 2007, 292, H3190-H3197. [CrossRef] [PubMed]

80. Hendrickson, R.J.; Cahill, P.A.; Sitzmann, J.V.; Redmond, E.M. Ethanol enhances basal and flow-stimulated nitric oxide synthase activity in vitro by activating an inhibitory guanine nucleotide binding protein. J. Pharmacol. Exp. Ther. 1999, 289, 1293-1300.

81. Wimmer, I.; Tietz, S.; Nishihara, H.; Deutsch, U.; Sallusto, F.; Gosselet, F.; Lyck, R.; Muller, W.A.; Lassmann, H.; Engelhardt, B. PECAM-1 stabilizes blood-brain barrier integrity and favors paracellular T-cell diapedesis across the blood-brain barrier during neuroinflammation. Front. Immunol. 2019, 10, 711. [CrossRef] [PubMed]

82. Rudolph, H.; Klopstein, A.; Gruber, I.; Blatti, C.; Lyck, R.; Engelhardt, B. Postarrest stalling rather than crawling favors CD8 ${ }^{+}$ over CD4 ${ }^{+}$T-cell migration across the blood-brain barrier under flow in vitro. Eur. J. Immunol. 2016, 46, 2187-2203. [CrossRef] [PubMed] 